\title{
Impact of Asymmetric Carbon Information on Supply Chain Decisions under Low-Carbon Policies
}

\author{
Lei Yang, Jingna Ji, and Chenshi Zheng \\ School of Economics and Commerce, South China University of Technology, Guangzhou, Guangdong 510006, China
}

Correspondence should be addressed to Lei Yang; yang@scut.edu.cn

Received 4 November 2015; Accepted 13 January 2016

Academic Editor: Manuel De la Sen

Copyright (C) 2016 Lei Yang et al. This is an open access article distributed under the Creative Commons Attribution License, which permits unrestricted use, distribution, and reproduction in any medium, provided the original work is properly cited.

Through the establishment of the leading manufacturer Stackelberg game model under asymmetric carbon information, this paper investigates the misreporting behaviors of the supply chain members and their influences on supply chain performance. Based on "Benchmarking" allocation mechanism, three policies are considered: carbon emission trading, carbon tax, and a new policy which combined carbon quota and carbon tax mechanism. The results show that, in the three models, the leader in the supply chain, even if he has advantages of carbon information, will not lie about his information. That is because the manufacturer's misreporting behavior has no effect on supply chain members' performance. But the retailer will lie about the information when he has carbon information advantage. The high-carbon-emission retailers under the carbon trading policy, all the retailers under the carbon tax policy, and the high-carbon-emission retailers under combined quotas and tax policy would like to understate their carbon emissions. Coordination of revenue sharing contract is studied in supply chain to induce the retailer to declare his real carbon information. Optimal contractual parameters are deduced in the three models, under which the profit of the supply chain can be maximized.

\section{Introduction}

During the past few years, the global carbon emissions have increased considerably. The thick haze events in recent years sounded the alarm to modern people [1]. People have realized that the events are closely related to the carbon emissions. Carbon emission has never been so much concerned by the public since it has been a great threat to the survival and health of human beings [2]. Overmuch carbon emissions can induce the increase of social cost, which damages the social welfare. It is imperative for governments around the world to impose effective policy instruments to promote energy saving and carbon emissions reduction [3]. Now the "cap-andtrade" and carbon tax policies are the two main low-carbon policies to curb carbon emissions. As the biggest developing country in the world, China is facing increasing pressure to reduce its carbon emissions. Thus, the Chinese government has established 7 carbon trading pilots over different cities, such as Beijing and Shanghai carbon trading markets. The reduction of carbon emission has become an inevitable trend and a worldwide consensus [4].
Carbon accounting is the basis of the implementation of low-carbon policies. For the enterprises that participate in the low-carbon reduction project, carbon quota and carbon emission information is the public information between the firms and the government. However, the carbon information is still opaque among the supply chain members. There are two main reasons. Firstly, the lack of unified carbon accounting standard renders the results unusable in other industries or regions. Secondly, in order to protect the business activities, the governments do not immediately publish the carbon information of enterprises. According to the survey of Accenture, in 2014, there are only 3396 companies involved in the global carbon disclosure, and most of them are large multinational companies. However, as a key component of carbon disclosure, carbon emission data is rarely disclosed. Among the disclosed information, the quality of data information is generally lower than that of the nondata information. As a result, the average score of the carbon information disclosure quality is only 53 points out of 100. The survey indicates that, at present, the whole consciousness of carbon disclosure among enterprises is weak 
and the quality of carbon information disclosure is not high. Thus, the carbon emission information is usually asymmetric among enterprises.

Asymmetric information is one of the causes lowering the efficiency of supply chains [5]. That is because the member that has information advantage would like to hide and even lie about his private information, so as to affect other members' decision and earn more profit. The misreporting behavior of one party may reduce the profits of the other party and the whole supply chain. With the implementation of low-carbon policies, carbon emission and carbon price information has also become the enterprises' private information. The asymmetric carbon information increases the difficulty of decision-making and will potentially lead to the misreporting behavior between supply chain members.

Research has shown that consumers have obvious preference for low-carbon products and are willing to pay more for environmentally friendly products [6]. In addition, some responsible retailers would like to cooperate with low-carbon-emission manufacturers. As important reference data, carbon emission and carbon price information will directly affect the decisions of enterprises. In particular, if a firm has no sufficient funds to improve its emission reduction technology and has carbon information priority, it may misreport its carbon information to gain a competitive advantage. Many studies have confirmed that asymmetric information has a significant impact on the decisions of supply chain members, such as the pricing, production, inventory, and order quantity decisions [7-9]. In addition, the pricing and order quantity decisions are proved to be influenced by low-carbon policies [10-12]. Based on the previous studies, we explicitly address the impact of asymmetry carbon information on the wholesale price decisions, order quantity decisions, and profits of the supply chain members.

In this paper, we investigate and compare the optimal supply chain decisions under different low-carbon policies in asymmetric carbon information situations, based on a two-echelon supply chain led by a manufacturer. Different effects of low-carbon policies on different types of firms are also discussed to provide theory basis for enterprises and government decision-making. Furthermore, a revenue sharing contract is established to motivate the party with information advantage to declare its real carbon information. This study has some realistic directive significance in the enterprise applications under low-carbon circumstance and has a role in promoting supply chain coordination study under asymmetric carbon information.

We organize the remainder of this paper as follows. Section 2 reviews the literature on low-carbon policies in operations management, carbon information disclosure, and supply chain coordination. In Section 3, we present assumptions and notations. Section 4 shows the misreporting solutions and comparisons of three low-carbon policies. In Section 5 , we focus on the issue of supply chain coordination for different models by using revenue sharing contract. Section 6 conducts numerical experiments to provide more insights. Conclusions and outlooks are finally presented in Section 7. To make the paper more readable, all proofs are presented in the Appendices.

\section{Literature Review}

This research is closely related to low-carbon policies in operations management, carbon information disclosure, and supply chain coordination. To highlight our contribution, we review only the literature that is representative and particularly relevant to our study.

2.1. Low-Carbon Policies in Operations Management. Lowcarbon policies have been recently studied by academic and industry researchers. In particular, their studies mainly relate to carbon trading policy and carbon tax policy, which is closely related to our study.

Carbon tax policy is investigated at both the macro and micro levels. From the macro perspective, many papers concerned the economic and environmental efficiency of carbon tax, such as Liu and Lu [13] and Allan et al. [14]. From the micro level, the existing literature has studied the impact of carbon tax policy on operations mainly from the perspective of pricing, production, and inventory decisions. Some of the related articles in this issue were presented by $\mathrm{Xu}$ et al. [11], He et al. [15], and Hammami et al. [16].

In addition to carbon tax policy, scholars also propose to use carbon trading policy to reduce emissions, which is proved to be an effective mechanism. For example, Sedjo and Marland [17] proved that permit trading should be tradable to reduce emissions and have a high degree of substitutability to interact in markets.

Compared with the above work, the following literature focuses on the comparison between two or more low-carbon policies. In this aspect, Benjaafar et al. [18] make a great contribution. They developed relatively simple models under low-carbon policies, including strict emission caps, taxes on emissions, cap-and-offset, and cap-and-trade policies, to discuss their impact on supply chain management decisions. Yang et al. [10] compared four kinds of low-carbon policies and investigate their influence on channel coordination. The above two studies aimed to present the comparison of different low-carbon policies, which is closely related to our study. However, we study the operation strategies with asymmetric carbon information under different low-carbon policies; in this aspect, their model differs from ours. Recently, Chiu et al. [19] considered the energy price equivalence with carbon tax and emission trading model. They detected that the economic effects of these two schemes on energy prices depend on the market structures.

Different from our research, the existing studies neglect to describe asymmetric carbon information in the supply chain. Therefore, this paper will contribute to this stream of literature by discussing the impact of asymmetry carbon information on the decisions and profits of the supply chain members under different low-carbon policies. Different effects of low-carbon policies on different types of firms are also discussed to provide theory basis for enterprises and government decision-making.

2.2. Carbon Information Disclosure. Carbon information disclosure is the most important and the most basic problem 
in carbon accounting. In low-carbon economy, carbon information disclosure is needed to be addressed and resolved. The research on carbon disclosure behavior mainly focuses on empirical study. For example, Stanny [20] investigated the carbon disclosure situation of the listed companies in the United States. He discovered that most companies have a positive attitude to the carbon disclosure but do not disclose their emission amounts or how they account for them.

Though the environmental awareness of the enterprises is increasing, the whole consciousness of carbon disclosure among enterprises is weak and the enterprises are not so active to participate in the carbon disclosure. Based on the present situations, many scholars have studied the factors affecting enterprises' positivity to participate in carbon disclosure and propose suggestions to improve the quality of corporate carbon disclosure. Huang [21] analyzed the carbon disclosure conditions of the listed companies in Chinese mainland. He putted forward the suggestion of constructing supervision system which listed companies' voluntary information to disclose. Peng et al. [22] investigated the carbon disclosure situation of China's listed companies. They detected that the enterprises operating in high-emission sectors tend to disclose more information.

At present, the carbon disclosure level of domestic and foreign enterprises is relatively low. The quality of carbon information disclosure varies in different enterprises. Serious carbon information asymmetry exists between enterprises. However, there is limited literature that studies the asymmetric carbon information phenomenon. Therefore, our paper will study the misreporting decision of the supply chain members and the coordination of the supply chain with asymmetry carbon information.

2.3. Supply Chain Coordination. Supply chain coordination is an important topic in today's increasingly complex environment. Various mechanisms for channel coordination have been proposed by scholars [23-25]. In this paper, we only briefly introduce the revenue sharing contract, which is closely related to our model.

Revenue sharing contract is firstly applied in video cassette rental industry. Mortimer [26, 27] demonstrated that the revenue sharing contract can improve the profit of supply chain in the video leasing industry. Cachon and Lariviere [28] used the revenue sharing contract to coordinate the supply chain with deterministic or stochastic demand. They detected that, in the newsvendor case, the revenue sharing contract is equivalent to buy back contract.

Due to the simple application, the revenue sharing contract is quickly prevalent to other industries. There are many scholars that research the extending application of this contract. Qin [29] establishes a two-echelon supply chain with Stackelberg game and discusses the conditions that can achieve the supply chain coordination. He focused on short life-cycle products, which is different from our research. Krishnan and Winter [30] proved that the revenue sharing contract cannot coordinate the supply chain with downstream competition. But in most cases, the revenue sharing contract mechanism can coordinate the supply chain.
Kong et al. [31] developed a two-echelon supply chain with one supplier and two competitive retailers. They analyzed the situation when the supplier reveals the order information of one retailer to another. The revenue sharing contract and wholesale price contract were used to coordinate the supply chain. Their results show that the revenue sharing contract can better motivate the supplier to provide feedback of the real information. Similarly, we use the revenue sharing contract in a two-echelon supply chain.

Revenue sharing contract is proved to be an effective way to coordinate supply chain with deterministic and disrupted demand. So, we introduce revenue sharing contract to coordinate supply chain in different low-carbon policies.

\section{Modeling}

3.1. Model Description. We investigate the pricing strategy and ordering decisions of supply chain members under three different low-carbon policies. A two-echelon model consisting of one manufacturer and one retailer is established. In our model, the manufacturer provides one kind of product for the retailer, and then the retailer sells the products to final consumers. The retailer is responsible for logistics and can further process products. The relationship between the manufacturer and retailer is modeled as a Stackelberg game, where the manufacturer is the leader and the retailer is the follower.

3.2. Notations. We list the following notations where $i$ ( $i=$ $m, r, \mathrm{sc})$ in subscripts are for the manufacturer, the retailer, and the supply chain, respectively, and $l(l=A, B)$ in subscripts are for the situation of the manufacturer that misreports the information and the situation of the retailer that misreports the information, respectively:

$p_{l}$ : unit price of the product.

$Q$ : order quantity under symmetric information.

$Q_{l}$ : order quantity in asymmetric information.

$w_{l}$ : unit wholesale price under asymmetric information.

$c_{i}$ : unit cost in the process of $i$ (not including carbon cost).

$e_{i}$ : average carbon price of $i$.

$\gamma_{i}$ : manufacturer's/retailer's misreporting factor about carbon emission, $\gamma_{i} \geq 0, i=m, r$.

$\eta_{i}$ : manufacturer's/retailer's misreporting factor about carbon price, $\eta_{i} \geq 0, i=m, r$.

$a_{M i}$ : carbon emission coefficient, $a_{M i}>0$.

$a_{\alpha i}$ : carbon quota coefficient, $a_{\alpha i}>0$.

$b_{M i}$ : fix carbon emission, $b_{e i}>0$.

$b_{\alpha i}$ : fix carbon quota, $b_{\alpha i}>0$.

$M_{i}$ : total carbon emissions of $i$.

$\alpha_{i}$ : total carbon quotas of $i$.

$f_{i}$ : the actual profit of $i$ under symmetric information. 
$f_{l i}$ : the actual profit of $i$ under asymmetric information.

$f_{\text {lih }}$ : the announced profit of $i$ under asymmetric information.

$A_{i}$ : confidence interval of carbon emission coefficient, $A_{i}=\left[a_{i L}, a_{i H}\right], a_{i H}>a_{i L}>0$ and $a_{M i} \in\left[a_{i L}, a_{i H}\right]$.

$E$ : fluctuation range of carbon price, $E=\left[e_{L}, e_{H}\right]$, $e_{H}>e_{L}>0$ and $e_{i} \in\left[e_{L}, e_{H}\right]$.

We develop our demand function according to [32, 33], which is a nonlinear demand function and is commonly used in the marketing and operations: $Q=D p^{-2 k}$, where $D$ is the potential market scale $(D>0)$ and $k$ is coefficient of price sensitivity $(k>1 / 2)$. Q can be regarded as the order quantity when the production can satisfy the market completely.

Carbon emissions occur along the whole life cycle of the product. In particular, most of them are produced in the processes of production, inventory, and transportation. There are two main ways to measure carbon emissions in the supply chain: $E(Q)=a Q[34]$ and $E(Q)=a Q+b[18,35]$. Considering the scale economic effect, we use $M_{i}(Q)=$ $a_{M i} Q+b_{M i}$ to describe the carbon emissions of supply chain members, where $a_{M i}$ is carbon emission coefficient and is associated with the technology level and $b_{M i}$ is the fix carbon emission and is associated with production capacity.

The total carbon quotas in the supply chain consist of manufacturer's carbon quotas and retailer's carbon quotas. There are two main free carbon quota allocation mechanisms: "Grandfathering" and "Benchmarking." With carbon quota allocation based on "Grandfathering" mechanism, firms get carbon quotas after carbon verification according to their historical emission data [36]. The "Benchmarking" methodology is established on the basis of average carbon emissions in certain industry. The total carbon quotas are associated with its production quantity. Compared to Grandfathering mechanism, the Benchmarking methodology can more effectively push facilities to make efficiency investments in reducing emissions. And the Benchmarking methodology is applied by EU-ETS, New Zealand Emission Trading Scheme (NZ ETS), and China [2]. Therefore, in our paper, we use the unit carbon quotas based on the Benchmarking, which can be regarded as the emission standard per unit. We assume that the carbon quotas of the supply chain, manufacturer, and retailer can be expressed as follows: $\alpha_{i}(Q)=a_{\alpha i} Q+b_{\alpha i}$. Then, $\alpha_{\text {sc }}(Q)=\alpha_{m}(Q)+\alpha_{r}(Q)$ and $a_{\alpha s c}=a_{\alpha m}+a_{\alpha r}$. We denote that the low-carbon-emission firms are those when $a_{\alpha i} \geq a_{m i}$ and $b_{\alpha i} \geq b_{m i}$, and the high-carbon-emission firms are those when $a_{\alpha i}<a_{m i}$ and $b_{\alpha i}<b_{m i}$.

In the model, we use parameters $\gamma_{i}$ and $\eta_{i}$ to measure the misreporting behavior of the supply chain members. Suppose that the manufacturer declares that his carbon emission is $\gamma_{m} M_{m}$ and carbon price is $\eta_{m} e_{m}$. The situation when $0<$ $\gamma_{m}<1$ denotes that the manufacturer understates his carbon emissions; the situation when $\gamma_{m}>1$ represents the notion that the manufacturer exaggerates his carbon emissions; the situation when $\gamma_{m}=1$ denotes that the manufacturer shows his true carbon emission information. The explanations of $\gamma_{r}$, $\eta_{m}$, and $\eta_{r}$ are similar to that of $\gamma_{m}$; thus, we omit them.

\subsection{Assumptions. We make the following assumptions:}

(1) The total carbon emissions from manufacturer's process and retailer process are both linear in production quantity [10, 37].

(2) The confidence interval of carbon emission coefficient is common knowledge to both supply chain players.

(3) The carbon quotas derived from the government can only be used in one certain period; the unused carbon quotas cannot be accumulated to the next period.

(4) The carbon price is determined by the carbon trading market.

(5) There is no misreporting behavior between enterprises and the government.

(6) The demand information and the cost information are public information to both supply chain players.

\section{Low-Carbon Supply Chain Operations under Asymmetric Carbon Information}

In reality, most of the companies are reluctant to participate in the carbon disclosure. As a result, asymmetric carbon information usually exists among enterprises. Under asymmetric carbon information, some enterprises may adopt misreporting strategy to gain higher profit when they have carbon information priority. In this section, we investigate the optimal misreporting decision of the manufacturer and the retailer with asymmetric carbon information situation under different low-carbon policies. The asymmetric carbon emission information and asymmetric carbon price information are both considered. The carbon policies include carbon emission trading, carbon tax, and a new policy which combined carbon quota and carbon tax mechanism. We use superscripts $j(j=a, b, c)$ to distinguish the low-carbon policies above, respectively.

4.1. Model a: Carbon Trading Model. Under the carbon trading regulation, firms will receive free carbon emission quotas from the government. And there is a carbon trading market in which the carbon quotas can be traded. In this subsection, we analyze the misreporting decisions of the manufacturer and the retailer, respectively.

4.1.1. The Misreporting Decision of the Manufacturer. If the manufacturer has carbon information priority, that is, the retailer's carbon information is known by the manufacturer but the manufacturer's carbon information is unknown by the retailer, he may misreport the information to increase his profit. Along with the improving environmental consciousness of consumers and retailers, it may be profitable for the manufacturer to lie about his carbon information. Such misreporting behavior can help the manufacturer gain more cooperation opportunity and sell more products. When the manufacturer chooses to misreport the carbon information, there exist double misreporting factors (carbon emission and carbon price). However, in reality, the manufacturer may not be able to misreport the two aspects at the same time. 
Therefore, we analyze three kinds of misreporting situations: double factors misreporting, single carbon emission factor misreporting, and single carbon price factor misreporting. We use superscripts $m(m=1,2,3)$ to distinguish the three misreporting situations above, respectively.

The sequence of the Stackelberg game is as follows. As the leader, the manufacturer declares a wholesale price according to the carbon information provided by the retailer. And then the retailer decides the order quantity according to the carbon information provided by the manufacturer. The announced profit of the manufacturer and the actual profit of the manufacturer and retailer are as follows:

$$
\begin{gathered}
f_{A m h}^{a}=\left(w_{A}^{a}-c_{m}\right) Q_{A}^{a}+\left(\alpha_{m}-\gamma_{m}^{a} M_{m}\right) \eta_{m}^{a} e_{m}^{a}, \quad=\frac{D(2 k-1)^{4 k}}{(2 k)^{4 k}\left(c_{\mathrm{sc}}+\gamma_{m}^{a} \eta_{m}^{a} a_{M m} e_{m}^{a}-\eta_{m}^{a} a_{\alpha m} e_{m}^{a}+a_{M r} e_{r}^{a}-a_{\alpha r}\right.} \\
f_{A m}^{a}=\left(w_{A}^{a}-c_{m}\right) Q_{A}^{a}+\left(\alpha_{m}-M_{m}\right) e_{m}^{a}, \quad \text { Under the equilibrium decisions, the profits } \\
f_{A r}^{a}=\left(p_{A}^{a}-w_{A}^{a}-c_{r}\right) Q_{A}^{a}+\left(\alpha_{r}-M_{r}\right) e_{r}^{a} . \quad \text { ufacturer and the retailer are } \\
f_{A m}^{a^{*}}=\frac{c_{\mathrm{sc}}+\left(a_{M r}-a_{\alpha r}\right) e_{r}^{a}+a_{M m} e_{m}^{a}\left(2 k \gamma_{m}^{a} \eta_{m}^{a}-2 k+1\right)-a_{\alpha m} e_{m}^{a}\left(2 k \eta_{m}^{a}-2 k+1\right)}{D^{-1}(2 k-1)^{1-4 k}(2 k)^{4 k}\left(c_{\mathrm{sc}}+\gamma_{m}^{a} \eta_{m}^{a} a_{M m} e_{m}^{a}-\eta_{m}^{a} a_{\alpha m} e_{m}^{a}+a_{M r} e_{r}^{a}-a_{\alpha r} e_{r}^{a}\right)^{2 k}+\left(b_{\alpha m}-b_{M m}\right) e_{m}^{a},} \\
D(2 k-1)^{4 k-2} \\
f_{A r}^{a^{*}}=\frac{D\left(b_{\alpha r}-b_{M r}\right) e_{r}^{a} .}{(2 k)^{4 k-1}\left(c_{\mathrm{sc}}+\gamma_{m}^{a} \eta_{m}^{a} a_{M m} e_{m}^{a}-\gamma_{c}^{a} a_{\alpha m} e_{m}^{a}+a_{M r} e_{r}^{a}-a_{\alpha r} e_{r}^{a}\right)^{2 k-1}}+(
\end{gathered}
$$

With Lemma 1, we can know that when $F_{1}>0$, there also exist optimal decisions and profits even though the manufacturer adopts misreporting strategy. If condition $F_{1}>$ 0 cannot be satisfied, the carbon information provided by the manufacturer is easy to be regarded as dummy message.

Theorem 2. For Model $a$, when $a_{M m} \neq a_{\alpha m}$, there exists the optimal misreporting equation $H_{1}=0$ that can maximize the manufacturer's profit under double factors misreporting strategy.

In order to analyze the impact of the supply chain's misreporting behaviors, we summarize the optimal wholesale price and order quantities for three models under symmetric information in Table 1.

According to Table 1, we can get the optimal profit of the manufacturer, retailer, and supply chain $f_{i}^{j^{*}}$ under symmetric information.

Corollary 3. Under the optimal misreporting equation $H_{1}=$ 0 , one can have $w_{A}^{a 1^{*}}=w^{a^{*}}, Q_{A}^{a 1^{*}}=Q^{a^{*}}, f_{A m}^{a 1^{*}}=f_{m}^{a^{*}}$, and $f_{A m}^{a 1^{*}}=f_{m}^{a^{*}}$.

With Corollary 3, we can conclude that the manufacturer' misreporting behavior has no influence on the decisions and profits of the supply chain members. It indicates that, under the carbon trading policy, the manufacturer as a leader has no motivation to adopt double factors misreporting strategy even if it has the advantages of carbon information. That is because his optimal misreporting strategy cannot improve his profit.
In the following paper, $F_{n}(n=1,2, \ldots, 8), H_{t}, I_{t}(t=$ $1,2)$, and $L$ are the threshold values and are given in Appendix G.

Lemma 1. For Model $a$, when the manufacturer has carbon information priority, there exist equilibrium solutions (optimal wholesale price and order quantity) in the supply chain if $F_{1}>$ 0 , where

$$
\begin{aligned}
& w_{A}^{a^{*}} \\
& =\frac{\left[c_{r}+a_{M r} e_{r}^{a}-a_{\alpha r} e_{r}^{a}+2 k\left(c_{m}+\gamma_{m}^{a} \eta_{m}^{a} a_{M m} e_{m}^{a}-\eta_{m}^{a} a_{\alpha m} e_{m}\right)\right]}{(2 k-1)}, \\
& Q_{A}^{a^{*}} \\
& =\frac{D(2 k-1)^{4 k}}{(2 k)^{4 k}\left(c_{\mathrm{sc}}+\gamma_{m}^{a} \eta_{m}^{a} a_{M m} e_{m}^{a}-\eta_{m}^{a} a_{\alpha m} e_{m}^{a}+a_{M r} e_{r}^{a}-a_{\alpha r} e_{r}^{a}\right)^{2 k}}
\end{aligned}
$$

Under the equilibrium decisions, the profits of the man-
With the improving environmental awareness, consumers consider more the low-carbon level when they choose products. Therefore, in order to attract more consumers, under the premise of ensuring the maximization of profit, the manufacturer may understate his carbon emissions. Under the influence of the confidence interval $A_{m}$, there exist certain boundary values when the manufacturer chooses to understate his carbon emission.

Theorem 4. Under the premise of ensuring the maximum profit, if the manufacturer chooses to understate his carbon emissions, the misreporting factors should satisfy the following conditions:

(1) If $a_{M m}>a_{\alpha m}$,

$$
\begin{aligned}
& F_{3}<a_{m H}, \quad \gamma_{m}^{a 1} \in\left[a_{M m}^{-1} F_{4}, a_{M m}^{-1} F_{3}\right] \\
& F_{4}<a_{m H}<F_{3}, \quad \gamma_{m}^{a 1} \in\left[a_{M m}^{-1} F_{4}, a_{M m}^{-1} a_{m H}\right] \\
& F_{4}>a_{m H}, \quad \varnothing .
\end{aligned}
$$

(2) If $a_{M m}<a_{\alpha m}$,

$$
\begin{aligned}
& F_{3}>a_{m L}, \quad \gamma_{m}^{a 1} \in\left[a_{M m}^{-1} F_{3}, a_{M m}^{-1} F_{4}\right] \\
& F_{3}<a_{m L}<F_{4}, \quad \gamma_{m}^{a 1} \in\left[a_{M m}^{-1} a_{m L}, a_{M m}^{-1} F_{4}\right] \\
& F_{4}<a_{m L}, \quad \varnothing .
\end{aligned}
$$

Theorem 4 shows the confidence interval of manufacturers' misreporting factor about carbon emission. Under 
TABLE 1: The optimal decisions for the three models under symmetric information.

\begin{tabular}{lcc}
\hline Carbon policies & Wholesale price $\left(w^{j^{*}}\right)$ & Order quantity $\left(Q^{j^{*}}\right)$ \\
Model a & $\frac{c_{r}+e_{r}^{a}\left(a_{M r}-a_{\alpha r}\right)+2 k\left(c_{m}+e_{m}^{a} a_{M m}-e_{m}^{a} a_{\alpha m}\right)}{2 k-1}$ & $\frac{D(2 k-1)^{4 k}}{(2 k)^{4 k}\left(c_{\mathrm{sc}}+e_{r}^{a} a_{M r}-e_{r}^{a} a_{\alpha r}+e_{m}^{a} a_{M s}-e_{m}^{a} a_{\alpha s}\right)^{2 k}}$ \\
Model b & $\frac{c_{r}+e_{r}^{b} a_{M r}+2 k\left(c_{m}+e_{m}^{b} a_{M s}\right)}{2 k-1}$ & $\frac{D(2 k-1)^{4 k}}{(2 k)^{4 k}\left(c_{\mathrm{sc}}+e_{r}^{b} a_{M r}+e_{m}^{b} a_{M s}\right)^{2 k}}$ \\
Model c & $\frac{c_{r}+e_{r}^{c}\left(a_{M r}-a_{\alpha r}\right)^{+}+2 k\left[c_{m}+e_{m}^{c}\left(a_{M m}-a_{\alpha m}\right)^{+}\right]}{2 k-1}$ & $\frac{D(2 k-1)^{4 k}}{(2 k)^{4 k}\left[c_{\mathrm{sc}}+e_{r}^{c}\left(a_{M r}-a_{\alpha r}\right)^{+}+e_{m}^{c}\left(a_{M m}-a_{\alpha m}\right)^{+}\right]^{2 k}}$ \\
\hline
\end{tabular}

Note. For Model a, the results are valid only when $F_{2}>0$; for Model c, $\left(a_{M r}-a_{\alpha r}\right)^{+}=\max \left\{\left(a_{M r}-a_{\alpha r}\right), 0\right\}$.

the influence of the confidence interval in a certain industry, manufacturers could not understate their carbon emissions indefinitely. Most of the manufacturers have the corresponding lowest misreporting factor about carbon emission. And there exist some enterprises that could not misreport their carbon emissions. For example, when any of the following situations occurs, the manufacturer is unable to understate his carbon emissions: (1) $a_{M m}=a_{\alpha m}$; (2) $e_{m}=e_{H}$; (3) $a_{M m}=a_{m L} ;(4) e_{m}=e_{L}$. With considering the leakage of carbon information, in the following, we further discuss the single carbon emission factor misreporting and single carbon price factor misreporting strategies.

Theorem 5. (1) The optimal single carbon emission misreporting strategy for the manufacturer is $\gamma_{m}^{a 2^{*}}=1$. (2) When $a_{M m} \neq$ $a_{\alpha m}$, the optimal single carbon price misreporting strategy for the manufacturer is $\eta_{m}^{a 3^{*}}=1$.

When the manufacturer can only misreport his carbon emission, he will get lower profit if he chooses to understate his carbon emissions. From the perspective of profit maximization, not only the low-carbon-emission manufacturer but also the high-carbon-emission manufacturer will declare his real carbon emission information. This conclusion is also applicable to the situation when $a_{M m}=a_{\alpha m}$.

When $a_{M m}=a_{\alpha m}$ and $\gamma_{m}^{a 3}=1$, the profit of the manufacturer shows irrelevance to carbon price. When the manufacturer can only misreport his carbon emission and $a_{M m} \neq a_{\alpha m}$, he will get lower profit if he lies about his carbon price. Therefore, the manufacturer will not choose single carbon price misreporting strategy even if it has the advantages of carbon price.

Conclusively, when the manufacturer can only choose single carbon emission/carbon price factor misreporting or when $a_{M m}=a_{\alpha m}$, the manufacturer will declare his real carbon information.

4.1.2. The Misreporting Decision of the Retailer. Under the carbon trading scheme, the retailer, the follower in the supply chain, may have the advantages of carbon information. Similar to the manufacturer, the retailer also has three kinds of misreporting strategies: double factors misreporting, single carbon emission factor misreporting, and single carbon price factor misreporting. We also use superscripts $m(m=$ $1,2,3)$ to distinguish the three misreporting situations above, respectively.

Suppose that the retailer's open carbon emission is $\gamma_{r} M_{r}$ and the open carbon price is $\eta_{r} e_{r}$. In order to obtain the manufacturer's trust, the retailer should vary his order quantity according to his announced profit. Then, the manufacturer will believe the carbon information provided by the retailer and make decisions. The announced profit of the retailer and the actual profit of the retailer and manufacturer are as follows:

$$
\begin{aligned}
f_{B r h}^{a} & =\left(p_{r}^{a}-w_{r}^{a}-c_{r}\right) Q_{r}^{a}+\eta_{r}^{a} e_{r}^{a}\left(\alpha_{r}-\gamma_{r}^{a} M_{r}\right), \\
f_{B r}^{a} & =\left(p_{r}^{a}-w_{r}^{a}-c_{r}\right) Q_{r}^{a}+e_{r}^{a}\left(\alpha_{r}-M_{r}\right), \\
f_{B m}^{a} & =\left(w_{r}^{a}-c_{m}\right) Q_{r}^{a}+\left(\alpha_{m}-M_{m}\right) e_{m}^{a} .
\end{aligned}
$$

Lemma 6. For Model a, when the retailer has carbon information priority, there exist equilibrium solutions (optimal wholesale price and order quantity) in the supply chain if $F_{5}>$ 0 , where

$$
\begin{aligned}
& w_{B}^{a^{*}} \\
& =\frac{\left[c_{r}+\gamma_{r}^{a} \eta_{r}^{a} a_{M r} e_{r}^{a}-\eta_{r}^{a} a_{\alpha r} e_{r}^{a}+2 k\left(c_{m}+a_{M m} e_{m}^{a}-a_{\alpha m} e_{m}^{a}\right)\right]}{(2 k-1)} \\
& Q_{B}^{a^{*}} \\
& =\frac{D(2 k-1)^{4 k}}{(2 k)^{4 k}\left(c_{\mathrm{sc}}+a_{M m} e_{m}^{a}-a_{\alpha m} e_{m}^{a}+\gamma_{r}^{a} \eta_{r}^{a} a_{M r} e_{r}^{a}-\eta_{r}^{a} a_{\alpha r} e_{r}^{a}\right)^{2 k}}
\end{aligned}
$$

Under the equilibrium decisions, the profits of the manufacturer and the retailer are $f_{B m}^{a^{*}}$ and $f_{B r}^{a^{*}}$, respectively.

With Lemma 6, we can know that when $F_{5}>0$, there also exist optimal decisions and profits even though the retailer lies about his carbon information. If condition $F_{5}>0$ cannot be satisfied, the carbon information provided by the retailer is easy to be regarded as dummy message.

Theorem 7. For Model $a$, when $\gamma_{c}^{a 1} a_{M r} \neq a_{\alpha r}$, there exists the optimal misreporting equation $\mathrm{H}_{2}=0$ that can maximize the retailer's profit under double factors misreporting strategy. 
When the retailer can misreport both his carbon emission and his carbon price, he will decide his order quantity according to the optimal misreporting equation above.

In order to invest the impact of retailer's misreporting behavior on the efficiency of the supply chain, we compare the decisions and profits in Lemma 6 with those in Table 1.

Corollary 8. Under the optimal misreporting equation $\mathrm{H}_{2}=$ 0 , one can have $w_{B}^{a 1^{*}}<w^{a^{*}}, Q_{B}^{a 1^{*}}>Q^{a^{*}}, f_{B r}^{a 1^{*}}>f_{r}^{a^{*}}, f_{B m}^{a 1^{*}}<$ $f_{m}^{a^{*}}$, and $f_{B s c}^{a 1^{*}}>f_{\mathrm{sc}}^{a^{*}}$.

With Corollary 8 we can conclude that the retailer's misreporting behavior will lower the wholesale price, improve the order quantity, and improve the efficiency of the supply chain. Under the optimal misreporting equation of the retailer, the profit of the retailer will improve, while the profit of the manufacturer will decrease. That is because the profit improvement from the order quantity is high enough to make up for the lost quantity from the price; thus, the supply chain can always benefit from the retailer's misreporting strategy. With Corollary 3, we can know that the manufacturer' optimal misreporting strategy has no influence on the profits of the retailer and the supply chain. In contrast, the retailer's optimal misreporting strategy will be detrimental to the profit of the manufacturer. From the perspective of the profit maximization, the retailer will misreport his carbon information when he has carbon information priority. However, the retailer's misreporting behavior makes the profit of the manufacturer reduce. The manufacturer, who is the leader in the supply chain, needs to establish an incentive mechanism to make the retailer with information advantage to declare their real carbon information.

Faced with consumers who have low-carbon preferences, the retailer also tends to understate his carbon emissions. Under the influence of the confidence interval $A_{r}$, there exist certain boundary values when the retailer chooses to understate his carbon emission.

Theorem 9. Under the premise of ensuring the maximum profit, if the retailer chooses to understate his carbon emissions, the misreporting factors should satisfy the following conditions:

(1) If $L>0$,

$$
\begin{aligned}
& F_{6}<a_{r H}, \quad \gamma_{r}^{a} \in\left[a_{M r}^{-1} F_{7}, a_{M r}^{-1} F_{6}\right] \\
& F_{7}<a_{r H}<F_{6}, \quad \gamma_{r}^{a} \in\left[a_{M r}^{-1} F_{7}, a_{M r}^{-1} a_{r H}\right] \\
& F_{7}>a_{r H}, \quad \varnothing .
\end{aligned}
$$

(2) If $L<0$,

$$
\begin{aligned}
& F_{6}>a_{r L}, \quad \gamma_{r}^{a} \in\left[a_{M r}^{-1} F_{6}, a_{M r}^{-1} F_{7}\right] \\
& F_{6}<a_{r L}<F_{7}, \quad \gamma_{r}^{a} \in\left[a_{M r}^{-1} a_{s L}, a_{M r}^{-1} F_{7}\right] \\
& F_{7}<a_{r L}, \quad \varnothing .
\end{aligned}
$$

(3) If $L=0$,

$$
\gamma_{r}^{a 1}=\frac{a_{\alpha r}}{a_{M r}}
$$

Theorem 4 shows the confidence interval of retailer's misreporting factor about carbon emission. Under the influence of the confidence interval in certain industry, the retailer could not understate his carbon emissions indefinitely. Most of the retailers have the corresponding lowest misreporting factor about carbon emission. With considering the leakage of carbon information, in the following, we further discuss the single carbon emission factor misreporting and single carbon price factor misreporting strategies.

Theorem 10. (1) The optimal single carbon emission misreporting strategy for the retailer is

$$
\begin{aligned}
\gamma_{r}^{a 2^{*}}= & \frac{\left(4 k^{2}-2 k\right)}{\left(4 k^{2}-2 k+1\right)} \\
& -\frac{\left(c_{\mathrm{sc}}+a_{M m} e_{m}^{a}-a_{\alpha m} e_{m}^{a}-a_{\alpha r} e_{r}^{a}\right)}{\left(4 k^{2}-2 k+1\right) a_{M r} e_{r}^{a}}, \\
\gamma_{r}^{a 2^{*}}< & 1 .
\end{aligned}
$$

(2) The optimal single carbon price misreporting strategy for the retailer is

$$
\begin{aligned}
& \eta_{r}^{a 3^{*}}= \frac{\left(4 k^{2}-2 k\right)}{\left(4 k^{2}-2 k+1\right)} \\
&-\frac{\left(c_{\mathrm{sc}}+a_{M m} e_{m}^{a}-a_{\alpha m} e_{m}^{a}\right)}{\left[\left(4 k^{2}-2 k+1\right)\left(a_{M r} e_{r}^{a}-a_{\alpha r} e_{r}^{a}\right)\right]}, \\
& \eta_{r}^{a 3^{*}}>1 \quad \text { if } a_{M r}<a_{\alpha r} \\
& \eta_{r}^{a 3^{*}}<1 \quad \text { if } a_{M r}>a_{\alpha r} .
\end{aligned}
$$

Under the carbon trading policy, when the retailer can only misreport his carbon emission, he will absolutely understate his carbon emissions to gain more profit. The retailer's single carbon price misreporting strategy shows relevance to the carbon emission and carbon quota coefficient. The highcarbon-emission retailer will understate his carbon price while the low-carbon-emission retailer will exaggerate his carbon price. Under the influence of $A_{r}$, the retailer cannot always gain the maximum profit. But if $A_{r}$ is big enough, the profit of the supply chain under single carbon price misreporting strategy is the same as the profit of the supply chain under double factor misreporting strategy; that is, $f_{B r}^{a 3^{*}}=f_{B r}^{a 1^{*}}$.

4.2. Model b: Carbon Tax Model. Under carbon tax policy, firms are charged for each unit of their carbon emission at a fixed tax rate level $s$ [25]. Such regulation will increase the cost of the enterprises directly, because the enterprises need to pay a fixed fee for each unit of carbon emission. We suppose that the fixed tax rate in carbon tax model is equivalent to 
the average carbon price in carbon trading model; namely, $e_{i}^{a}=s(i=m, r, \mathrm{sc})$. In the carbon tax model, there only exists asymmetric carbon emission information for the carbon tax is public information.

4.2.1. The Misreporting Decision of the Manufacturer. Under the circumstance that the retailer has no knowledge of the manufacturing carbon information, this subsection mainly investigates the behaviors of the manufacturer's misreporting and analyzes the impacts of these behaviors on supply chain operation. When the manufacturer wants to lie about his carbon emission information, the announced profit of the manufacturer and the actual profit of the manufacturer and retailer are as follows:

$$
\begin{aligned}
f_{A m h}^{b} & =\left(w_{A}^{b}-c_{m}\right) Q_{A}^{b}-\gamma_{m}^{b} e_{m}^{b} M_{m} \\
f_{A m}^{b} & =\left(w_{A}^{b}-c_{m}\right) Q_{A}^{b}-e_{m}^{b} M_{m} \\
f_{A r}^{b} & =\left(p_{m}^{b}-w_{A}^{b}-c_{r}\right) Q_{A}^{b}-e_{r}^{b} M_{r} .
\end{aligned}
$$

Theorem 11. In Model b, the optimal carbon emission misreporting strategy for the manufacturer is $\gamma_{m}^{b^{*}}=1$.

Under the carbon tax model, the manufacturer will declare his real carbon emission information to maximize his profit. Different from the carbon trading model, there exists no confidence interval of carbon emission in the carbon tax model. Therefore, this conclusion is applicable to the supply chains dominated by manufacturers.

4.2.2. The Misreporting Decision of the Retailer. When the retailer wants to lie about his carbon emission information, the announced profit of the retailer and the actual profit of the retailer and manufacturer are as follows:

$$
\begin{aligned}
f_{B r h}^{b} & =\left(p_{B}^{b}-w_{B}^{b}-c_{r}\right) Q_{B}^{b}-\gamma_{r}^{b} e_{r}^{b} M_{r}, \\
f_{B r}^{b} & =\left(p_{B}^{b}-w_{B}^{b}-c_{r}\right) Q_{B}^{b}-e_{r}^{b} M_{r}, \\
f_{B s}^{b} & =\left(w_{B}^{b}-c_{m}\right) Q_{B}^{b}-e_{m}^{b} M_{m} .
\end{aligned}
$$

Theorem 12. The optimal carbon emission misreporting strategy for the retailer is

$$
\begin{aligned}
\gamma_{r}^{b^{*}} & =\frac{\left(4 k^{2}-2 k\right)}{\left(4 k^{2}-2 k+1\right)}-\frac{\left(c_{\mathrm{sc}}+a_{M m} e_{m}^{b}\right)}{\left(4 k^{2}-2 k+1\right) a_{M r} e_{r}^{b}}, \\
\gamma_{r}^{b^{*}} & <1 .
\end{aligned}
$$

Under the carbon tax policy, the retailer can only misreport his carbon emission. From Theorem 12, we can know that the optimal misreporting strategy for the retailer is to understate his carbon emissions. When the retailer lies about his carbon emissions according to $\gamma_{r}^{b^{*}}$, the profit of the retailer and the supply chain is $f_{B r}^{b^{*}}$ and $f_{B s c}^{b^{*}}$, respectively. In order to invest the impact of retailer's misreporting behavior on the efficiency of the supply chain, we compare the decisions and profits in Theorem 12 with those in Table 1.
Corollary 13. Under the optimal misreporting factor $\gamma_{r}^{b^{*}}$, one can have $Q_{B}^{b^{*}}>Q^{b^{*}}, f_{B r}^{b^{*}}>f_{r}^{b^{*}}$, and $f_{B s c}^{b^{*}}>f_{\mathrm{sc}}^{b^{*}}$.

With Corollary 13, we can conclude that the retailer's misreporting behavior will increase the order quantity and improve the profit of both the retailer and the supply chain. With Theorem 12, we can conclude that, under the carbon tax policy, the retailer will understate his carbon emission information when he has carbon information priority. However, the retailer's misreporting behavior makes the profit of the manufacturer reduce. Therefore, it is imperative for the manufacturer to impose effective mechanism to induce the retailer to declare his real carbon information.

Theorem 14. Under the influence of $A_{r}$, if the retailer chooses to understate his carbon emissions, the misreporting factors should satisfy the following conditions:

(1) If $a_{m r} \neq a_{R L}$

$$
\begin{aligned}
& \gamma_{r}^{b^{*}}=F_{8}<1, \\
& f_{B r}^{b^{*}}\left(\gamma_{r}^{b^{*}}\right)>f_{r}^{b^{*}} \\
& \quad \text { if } F_{8} \in\left[\frac{a_{r L}}{a_{M r}}, \frac{a_{H}}{a_{M r}}\right] \\
& \gamma_{r}^{b^{*}}=\frac{a_{r L}}{a_{M r}}<1, \\
& f_{B r}^{b^{*}}\left(\frac{a_{r L}}{a_{M r}}\right)>f_{r}^{b^{*}} \\
& \quad \text { if } F_{8} \in\left(0, \frac{a_{r L}}{a_{m r}}\right)
\end{aligned}
$$

$\varnothing \quad$ if $F_{8} \in(-\infty, 0)$.

(2) If $a_{m r}=a_{r L}$,

$$
\gamma_{r}^{b^{*}}=1
$$

Under the influence of $A_{r}$, some retailers cannot obtain the maximum profit. But they can gain the suboptimum profit through understating their carbon emissions. When $a_{m r}=a_{r L}$, the retailer will declare his real carbon emission information.

Conclusively, without considering the confidence interval $A_{r}$, the retailer will absolutely understate his carbon emissions. When considering the influence of confidence interval $A_{r}$, some retailers may be unable to misreport their carbon information. In any case, the retailer will not exaggerate his carbon emissions.

4.3. Model c: Combined Quotas and Tax Model. Under the carbon trading policy, the fluctuations of carbon price will lead to market imbalances. With carbon tax policy, enterprises may pay much for their overmuch carbon emissions [38]. Therefore, the carbon tax policy is difficult to accept by the firms. Based on the above reasons, we introduce 
a new regulation: combined quotas and tax model. Under such policy, firms can also get free carbon quotas from the government. But there exists no carbon trading market. The carbon quotas of the supply chain members cannot buy/sell on the market. At the end of the carbon accounting, if the actual carbon emissions exceed the carbon quotas, the amount of the excessive quotas is required to pay carbon tax. The excessive parts need to be taxed by the government.

4.3.1. The Misreporting Decision of the Manufacturer. In the combined quotas and tax model, there usually exists carbon emission information misreporting behavior. With different carbon emission misreporting decisions, price misreporting usually has two cases: (1) the firms declare that they did not pay for the tax, but actually they pay for the tax, and (2) the firms declare that they pay for some of the tax, but actually they pay for all the tax. When the manufacturer wants to lie about his carbon emission information, the announced profit of the manufacturer and the actual profit of the manufacturer and retailer are as follows:

$$
\begin{gathered}
f_{A s h}^{c}=\left(w_{A}^{c}-c_{m}\right) Q_{A}^{c}-e_{m}^{c}\left(\gamma_{m}^{c} M_{m}-\alpha_{m}\right)^{+}, \\
f_{A s}^{c}=\left(w_{A}^{c}-c_{m}\right) Q_{A}^{c}-e_{m}^{c}\left(M_{m}-\alpha_{m}\right)^{+}, \\
f_{A r}^{c}=\left(p_{A}^{c}-w_{A}^{c}-c_{r}\right) Q_{A}^{c}-e_{r}^{c}\left(M_{r}-\alpha_{r}\right)^{+} .
\end{gathered}
$$

Theorem 15. The optimal carbon emission misreporting strategies for the manufacturer are as follows:

$$
\begin{aligned}
& \gamma_{m}^{c^{*}} \in\left[\frac{a_{s L}}{a_{M m}}, \frac{a_{\alpha m}}{a_{M m}}\right] \quad \text { if } a_{M m} \leq a_{\alpha m} \\
& \gamma_{m}^{c^{*}}=1 \quad \text { if } a_{M m}>a_{\alpha m} .
\end{aligned}
$$

With Theorem 15, we can know that the manufacturer's misreporting decision shows relevance to the carbon emission and carbon quota coefficient. When $a_{M m} \leq a_{\alpha m}$, there exists optimal misreporting interval for the manufacturer. The manufacturer can choose to understate his carbon emissions, exaggerate his carbon emissions, or declare his real carbon information. Within the interval, the manufacturer cannot obtain additional profit through misreporting behavior. That is because, in the combined quotas and tax scheme, the redundant carbon quotas of the supply chain members cannot sell on the market. When $a_{m s}>a_{\alpha s}$, the manufacturer would like to declare his real carbon information.

We can also conclude that, in order to maximize the profit, the high-carbon-emission manufacturer must declare his real carbon information, while the low-carbon-emission manufacturer can misreport his carbon information within the interval $\left[a_{s L} / a_{M m}, a_{\alpha m} / a_{M m}\right]$.

Corollary 16. Under the optimal misreporting factor $\gamma_{m}^{c^{*}}$, one can have $Q^{c^{*}}=Q_{A}^{c^{*}}, w^{c^{*}}=w_{A}^{c^{*}}, f_{A m}^{c^{*}}=f_{m}^{c^{*}}$, and $f_{A r}^{c^{*}}=f_{r}^{c^{*}}$.

With Corollary 16, we can conclude that the manufacturer's misreporting behavior has no influence on the decisions and profits of the supply chain members. It indicates that, under the combined quotas and tax model, the manufacturer as a leader has no motivation to adopt misreporting strategy even if it has the advantages of carbon information. That is because his optimal misreporting strategy cannot improve his profit.

4.3.2. The Misreporting Decision of the Retailer. When the retailer wants to lie about his carbon emission information, the announced profit of the retailer and the actual profit of the retailer and manufacturer are as follows:

$$
\begin{aligned}
f_{B r h}^{c} & =\left(p_{B}^{c}-w_{B}^{c}-c_{r}\right) Q_{B}^{c}-e_{r}^{c}\left(\gamma_{r}^{c} M_{r}-\alpha_{r}\right)^{+}, \\
f_{B r}^{c} & =\left(p_{B}^{c}-w_{B}^{c}-c_{r}\right) Q_{B}^{c}-e_{r}^{c}\left(M_{r}-\alpha_{r}\right)^{+}, \\
f_{B s}^{c} & =\left(w_{B}^{c}-c_{s}\right) Q_{B}^{c}-e_{m}^{c}\left(M_{m}-\alpha_{m}\right)^{+} .
\end{aligned}
$$

Theorem 17. The optimal carbon emission misreporting strategies for the retailer are as follows:

$$
\begin{aligned}
\gamma_{r}^{c^{*}} & \in\left[\frac{a_{r L}}{a_{M r}}, \frac{a_{\alpha r}}{a_{M r}}\right] \quad \text { if } a_{M r} \leq a_{\alpha r} \\
\gamma_{r}^{c^{*}} & =\frac{4 k^{2}-2 k}{I_{1}}-\frac{I_{2}}{I_{1} a_{M r} e_{r}^{c}}, \\
\gamma_{r}^{c^{*}} & <1
\end{aligned}
$$

$$
\text { if } a_{M r}>a_{\alpha r} \text {. }
$$

Theorem 17 shows that, in the combined quotas and tax model, the retailer's optimal misreporting decision depends on his carbon emissions. There exists optimal misreporting interval for the low-carbon-emission retailer. Within the interval, retailer's profit with misreporting strategy is the same as that without misreporting strategy. In this case, the low-carbon-emission retailer has no motivation to misreport his carbon information. On the contrary, the optimal strategy for the high-carbon-emission retailer is to understate his carbon emissions. There may also exist optimal misreporting factor or interval for the high-carbon-emission retailer.

Corollary 18. In Model $c$, when $a_{M r}>a_{\alpha r}$, under the optimal misreporting factor $\gamma_{r}^{c^{*}}$, one can have $Q_{B}^{c^{*}}>Q^{c^{*}}, f_{B s c}^{c^{*}}>f_{\mathrm{sc}}^{c^{*}}$.

With Corollary 18, we can conclude that the low-carbonemission retailer's misreporting behavior has no influence on his profits and the profits of the supply chain, while the highcarbon-emission retailer's optimal misreporting behavior will help increase his profit and the profit of the whole supply chain.

4.4. Comparisons of the Three Models. In this subsection, we compare the misreporting decisions under different carbon policies. For ease of discussion, in this subsection, we suppose that the carbon price/carbon tax in the three models is the same and ignore considering the influence of confidence interval in the industry. The optimal misreporting strategies for the supply chain members under the three models are summarized in Table 2. 
TABLE 2: The optimal misreporting strategies for the three models under symmetric information.

\begin{tabular}{|c|c|c|}
\hline Carbon policies & Optimal strategy for the manufacturer & Optimal strategy for the retailer \\
\hline Model a & $\begin{array}{c}\gamma_{m}^{a 1^{*}}=\eta_{m}^{a 1^{*}}=1 \quad \text { if } a_{M m}=a_{\alpha m} \\
H_{1}=0 \quad \text { if } a_{M m} \neq a_{\alpha m} \\
\gamma_{m}^{a 2^{*}}=1, \quad \eta_{m}^{a 3^{*}}=1\end{array}$ & $\begin{array}{c}H_{2}=0 \quad \text { if } \gamma_{c}^{a 1} a_{M r} \neq a_{\alpha r} \\
\gamma_{r}^{a 2^{*}}<1 \\
\eta_{r}^{a 3^{*}}>1 \quad \text { if } a_{M r}<a_{\alpha r} \\
\eta_{r}^{a 3^{*}}<1 \quad \text { if } a_{M r}>a_{\alpha r}\end{array}$ \\
\hline Model b & $\gamma_{m}^{b^{*}}=1$ & $\gamma_{r}^{b^{*}}<1$ \\
\hline Model c & $\begin{array}{c}\gamma_{m}^{c^{*}} \leq \frac{a_{\alpha m}}{a_{M m}} \quad \text { if } a_{M m} \leq a_{\alpha m} \\
\gamma_{m}^{c^{*}}=1 \quad \text { if } a_{M m}>a_{\alpha m}\end{array}$ & $\begin{aligned} \gamma_{r}^{c^{*}} \leq \frac{a_{\alpha r}}{a_{M r}} & \text { if } a_{M r} \leq a_{\alpha r} \\
\gamma_{r}^{c^{*}}<1 & \text { if } a_{M r}>a_{\alpha r}\end{aligned}$ \\
\hline
\end{tabular}

With the above theorems, we make a brief summary (1)(3) to present the manufacturer's and the retailer's misreporting strategies under each model. Then, we compare the three models and obtain the conclusions (4)-(7):

(1) For Model $a$, the manufacturer's optimal double factors misreporting strategy has no influence on the profits of the supply chain members. The retailer's optimal misreporting behavior is proved to be profitable for him and the supply chain, but it is detrimental to the manufacturer. In addition, if the manufacturer can only choose single carbon emission/carbon price factor misreporting, he will absolutely declare his real information. However, if the retailer can only lie about his carbon emission, he will understate it. When the retailer can only misreport his carbon price, then a high-carbon-emission retailer will understate his carbon price; by contrast, a low-carbon-emission retailer will exaggerate his carbon price.

(2) For Model b, the manufacturer's optimal strategy is to declare his real carbon information; the retailer's optimal misreporting strategy is to understate his carbon emissions, and such strategy can help him earn more profit.

(3) For Model c, even though the manufacturer chooses the optimal misreporting strategy which is to understate his carbon emissions, he cannot gain more profit. In addition, it is profitless for the low-carbonemission retailer to misreport his information, while it is profitable for the high-carbon-emission retailer to understate his carbon emissions.

(4) The manufacturers, who are the leader in the supply chain, have no occasion to misreport their carbon information; namely, $\gamma_{m}^{j^{*}}=1(j=a, b, c)$. With considering consumers' low-carbon preference, some manufacturers may understate their carbon emissions under the carbon trading policy and the combined quotas and tax policy. Further, the misreporting behaviors have no influence on the profit of the supply chain.

(5) The retailers, who are in the subordinate position, will lie about the carbon information to increase their profit if they have carbon information advantages. The high-carbon-emission retailers under the carbon trading policy, all the retailers under the carbon tax policy, and the high-carbon-emission retailers under combined quotas and tax policy will understate their carbon emissions to increase profits. Under the combined quotas and tax policy, the low-carbon-emission retailers can obtain the maximum profits though without any misreporting behaviors. When the other conditions remain unchanged, all the low-carbonemission retailers can obtain the same optimal profits under the combined quotas and tax policy.

(6) In the carbon tax model, there exists unique misreporting solution for the manufacturer. In the other two models, manufacturers' misreporting decisions show relevance to the carbon emission and carbon quota coefficient. When considering the optimal misreporting strategies for the retailers, we can get $\gamma_{r}^{a^{*}}<$ $\gamma_{r}^{c^{*}} \leq \gamma_{r}^{a 2^{*}}<1$. And the optimal misreporting factors are negatively related to the carbon emission coefficient of the manufacturer and positively related to the carbon emission coefficient of the manufacturer. It indicates that the retailers' misreporting strategies will be different because of different partners. The information provided by the retailer is more close to the real value when the retailer cooperates with a lowcarbon-emission manufacturer.

(7) There exist carbon information misreporting behaviors in the three policies. When the enterprises decide whether or not to misreport their carbon information according to their profits, then the misreporting behaviors are slightly less in the combined quotas and tax policy than that in the other two policies. Due to the existence of double misreporting factors, the misreporting phenomenon is more complex under the carbon trading policy, which is conductive to the orderly operation of the carbon market. For the supply chain, it can get higher profit in the carbon trading policy than that in the other two policies if the retailer misreports his carbon information; namely, $f_{B m}^{a^{*}} \geq f_{B m}^{c^{*}}>f_{B m}^{b^{*}}$ and $f_{B r}^{a^{*}} \geq f_{B r}^{c^{*}}>f_{B r}^{b^{*}}$. 


\section{Low-Carbon Supply Chain Coordination with Revenue Sharing Contract}

From the above analysis, we can know that the manufacturer needs to establish an incentive mechanism to induce the retailer with information priority to show his true carbon information. To this end, some appropriate contracts can be adopted. This section we will use revenue sharing contract to analyze the coordination under asymmetric carbon information. We use superscripts $t(t=A, B, C)$ to distinguish the three low-carbon policies.

With a revenue sharing contract, the retailer can obtain the products from the manufacturer with a discounted price. After selling the products, the retailer should share his revenue with the manufacturer at a certain revenue sharing rate $\phi(0 \leq \phi \leq 1)$. Under the asymmetric carbon information, the manufacturer is not able to obtain the real information from the retailer. Take the carbon trading model as an example; with Section 4.1, we can know that the misreporting behavior of the manufacturer has no effect on the profit of the supply chain, while the misreporting behavior of the retailer will change the balance of the original profit. In order to eliminate the loss from the asymmetric carbon information, the manufacturer uses revenue sharing contract to induce the retailer with information priority to show his true carbon information. Suppose that $e_{m}^{a}=e_{r}^{a}=e_{\mathrm{sc}}^{a}$.

With the revenue sharing contract $\left(w^{A}, \phi^{A}\right)$, the announced profit of the retailer and the actual profit of the retailer and manufacturer are as follows:

$$
\begin{aligned}
f_{r h}^{A}= & {\left[\left(1-\phi^{A}\right) p^{A}-w^{A}-c_{r}\right] Q^{A} } \\
& +\eta_{r}^{A} e_{r}^{a}\left[\alpha_{r}\left(Q^{A}\right)-\gamma_{r}^{A} M_{r}\left(Q^{A}\right)\right], \\
f_{r}^{A}= & {\left[\left(1-\phi^{A}\right) p^{A}-w^{A}-c_{r}\right] Q^{A} } \\
& +e_{r}^{a}\left[\alpha_{r}\left(Q^{A}\right)-M_{r}\left(Q^{A}\right)\right], \\
f_{s}^{A}= & \left(w^{A}-c_{m}\right) Q^{A}+e_{m}^{a}\left[\alpha_{m}\left(Q^{A}\right)-M_{m}\left(Q^{A}\right)\right] \\
& +\phi^{A} p^{A} Q^{A} .
\end{aligned}
$$

Similarly, we can get the profit functions in the carbon tax model and the combined quotas and tax model; here, we omit them. With the revenue sharing contract, we can get the following theorem.

Theorem 19. In model $j(j=a, b, c)$, the retailer will declare his real carbon information when $\phi^{t^{*}}=1 /(2 k+1), t=A, B, C$.

The optimal contractual parameters are deduced in Theorem 19. A unique revenue sharing fraction is proved to coordinate the whole supply chain based on revenue sharing contract mechanism. We can learn from the theorem that when the revenue sharing fraction $\phi^{t^{*}}=1 /(2 k+1)$, the retailer will declare his real carbon information. It indicates that the revenue sharing contract can help to promote information sharing between the supply chain members under asymmetric carbon information in the three models.

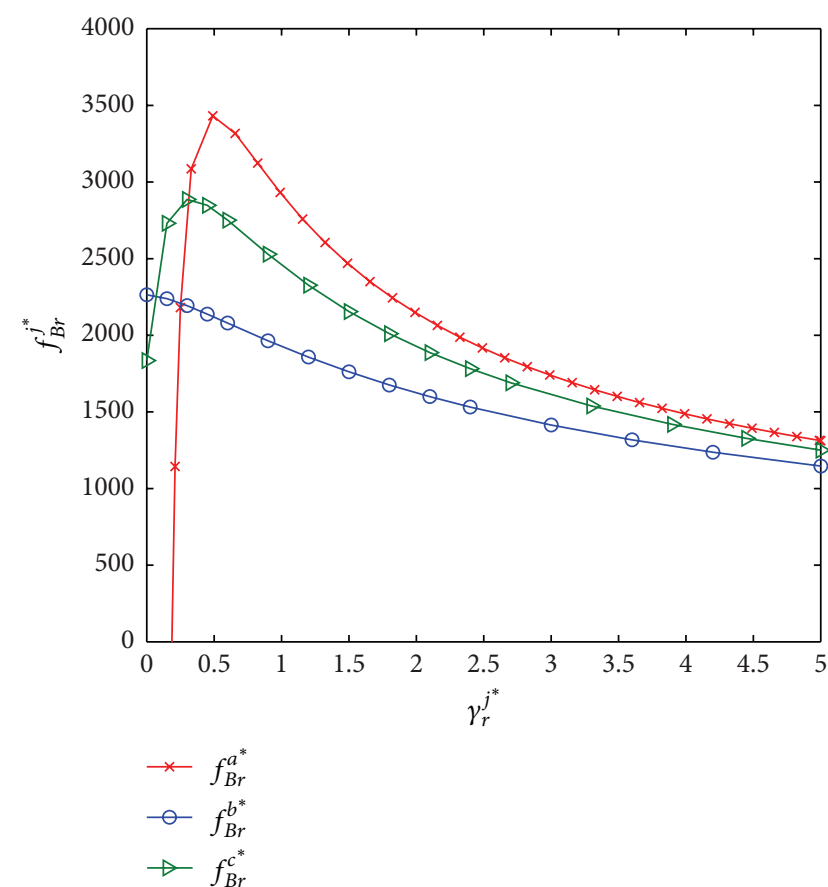

FIGURE 1: Without revenue sharing contracts.

In addition, if $\phi^{t^{*}}$ can satisfy $f_{r}^{t^{*}} \geq f_{B r}^{j^{*}}$ and $f_{m}^{t^{*}} \geq f_{B m}^{j^{*}}$ at the same time, the revenue sharing contract can make the supply chain realize Pareto improvement. $f_{\mathrm{Br}}^{j^{*}}$ and $f_{\mathrm{Bm}}^{j^{*}}$ are the actual profit of the retailer and the manufacturer under retailer's optimal misreporting strategy. With $f_{B r}^{j^{*}}>$ $f_{r}^{j^{*}}$, we can know that the retailer can gain higher profit with asymmetric carbon information than that with systemic carbon information. Therefore, in order to achieve supply chain coordination, the manufacturer should pay additional information cost for the retailer.

\section{Numerical Analysis}

In this section, we investigate the effectiveness of the revenue sharing contract. Then, we derive the cooperative conditions, under which the retailer will accept the revenue sharing contract. The most interesting problem we want to verify is whether the designed contract is profitable for all the supply chain members.

Since it is hard to obtain the accurate data from the enterprises, we give some estimated parameters to show the difference between the cases without and with revenue sharing contracts. The parameter values used in this section are as follows: $D=100000, c_{\mathrm{sc}}=10, e_{\mathrm{sc}}^{a}=e_{\mathrm{sc}}^{b}=e_{\mathrm{sc}}^{c}=5$, $a_{M m}=1, a_{\alpha m}=2, a_{M r}=3, a_{\alpha r}=1$, and $k=0.8$. There exists optimal contract parameter $\phi_{2}^{t^{*}}=1 /(2 k+1)(t=A, B, C)$ in each model. For ease of discussion, we suppose that $\eta_{r}^{A}=1$ and $b_{M i}=b_{\alpha i}=0$.

Figures 1 and 2 depict the curves of the retailer's profit in different model with respect to $\gamma_{r}$. With Figure 1, we can know that, without the revenue sharing contract, there exists different optimal misreporting factor about carbon emissions 


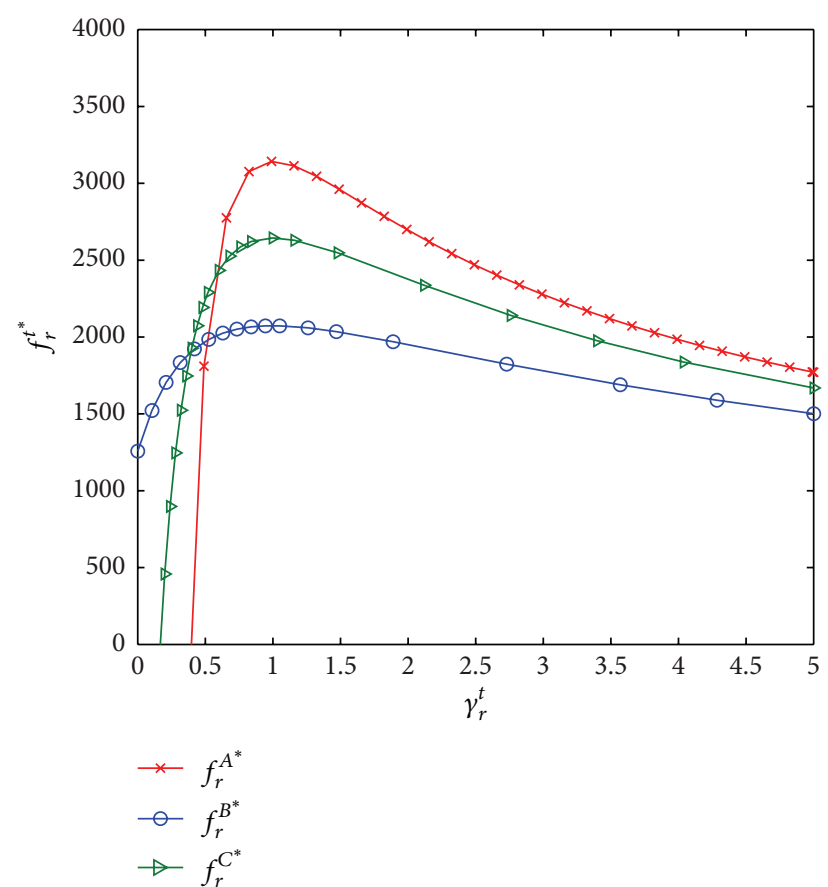

FIGURE 2: With revenue sharing contracts.

for the retailer. And all of the three optimal misreporting factors are less than 1. After adopting the revenue sharing contract with $\phi_{2}^{j^{*}}=1 /(2 k+1)$, the retailers' optimal misreporting factors in the three models are equal to 1 (Figure 2). It indicates that the revenue sharing contract can indeed stimulate the supply chain members to share their carbon information.

In addition, the contract can be accepted by the supply chain members only when both members can get higher profit after the coordination. The retailers' profits with and without revenue sharing contract are analyzed above. Thus, we further consider the profit of the manufacturer and the supply with $\phi_{2}^{j^{*}}=1 /(2 k+1)$. The optimal coordination strategies and contract parameters in each model are the same. Thus, we just take the carbon trading model as an example, to analyze the profit of the manufacturer and the supply chain with/without revenue sharing contract.

Figure 3 depicts the curves of the manufacturer's profit with respect to $k$. Figure 4 depicts the curves of the supply chain's profit. Figures 3 and 4 show that both the manufacturer and the supply chain can gain higher profits after the use of revenue sharing contract. With Figures 3 and 4 , we can conclude that retailer's profit with revenue sharing contract is higher than the profit without misreporting strategy, but lower than the profit with misreporting strategy $(k=0.8)$. In order to encourage the retailer to accept the contract, the manufacturer can pay some information cost $T^{A}$ to the retailer. And $T^{A}$ should satisfy $T^{A} \geq f_{B r}^{a^{*}}-f_{r}^{A}$ and $T^{A} \leq f_{m}^{A^{*}}-f_{B m}^{a^{*}}$. With Figure 4 , we can know that $f_{\mathrm{sc}}^{A^{*}}>f_{B s c}^{a^{*}}$; thus, $T^{A}$ exists. With the revenue sharing coefficient and transfer payment, the retailer would like to declare his real carbon information. Consequently, the supply chain can realize Pareto improvement.



Figure 3: The profit of the manufacturer.

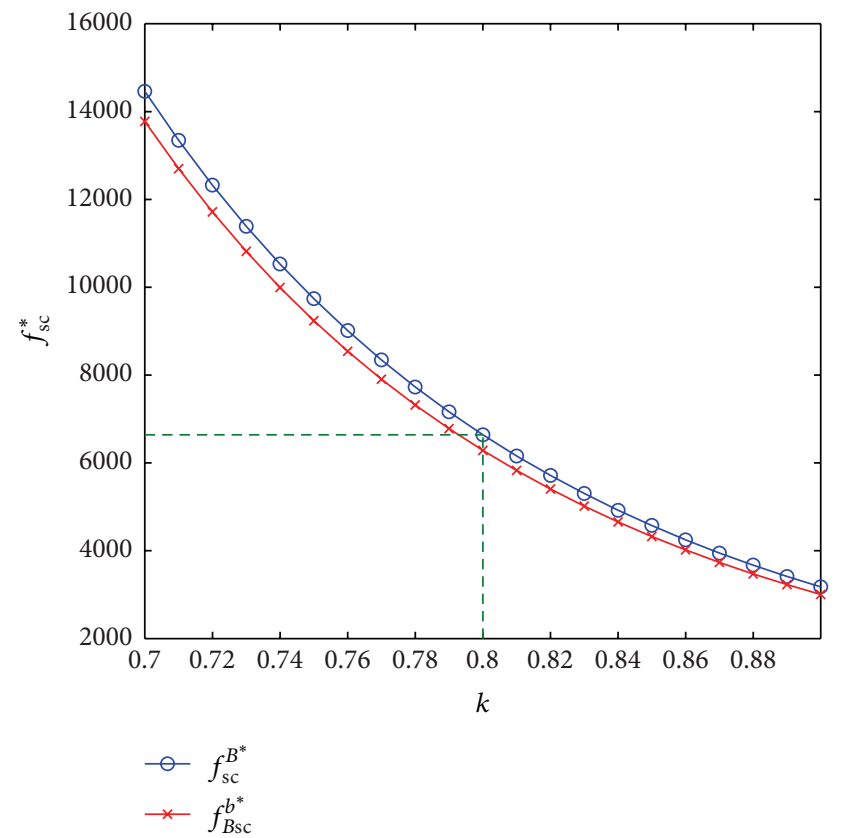

FIGURE 4: The profit of the supply chain.

Under the asymmetric carbon information, the optimal coordination strategies and contract parameters in the carbon trading model, carbon tax model, and combined quotas and tax model are the same. And the figures of the manufacturer's profit and the supply chain's profit in the carbon tax model and the combined quotas and tax model are similar to the figures in the carbon trading model; thus, we omit them. It has been verified by numerical simulation that the designed contract can guarantee that the profit of members in both the carbon tax model and the combined quotas and tax model is 
better after the use of revenue sharing contract. There also exist transfer payments $T^{B}$ and $T^{C}$ that can stimulate the retailer to accept the revenue sharing contract. The contract can induce the retailer with information priority to show his true carbon information. Thus, the supply chain can realize Pareto improvement. That is to say, the contract is effective and executable.

\section{Concluding Remarks and Future Research}

This paper studies the optimal supply chain decisions under different low-carbon policies in asymmetric carbon information situations, based on a two-echelon supply chain led by a manufacturer. To this end, the carbon emission trading policy, carbon tax policy, and a new policy which combined carbon quota and carbon tax mechanism are designed in the theoretical model, while low-carbon-emission firms and high-carbon-emission firms are taken into consideration. Different effects of low-carbon policies on different types of firms are also discussed to provide theory basis for enterprises and government decision-making.

This paper discusses the optimal misreporting decisions of the supply chain members and the impacts of misreporting on supply chain in the asymmetric information situation under low-carbon policies. The results imply that manufacturer and retailer have different misreporting decisions in different low-carbon policies. The manufacturers, who are the leader in the supply chain, have no occasion to lie about their carbon information in the three models. With considering consumers' low-carbon preference, some manufacturers may understate their carbon emissions under the carbon trading policy and the combined quotas and tax policy. Further, the misreporting behaviors have no influence on the profit of the supply chain. The retailers, who are in the subordinate position, will lie about the carbon information to increase their profit if they have carbon information advantages. The high-carbon-emission retailers under the carbon trading policy, all the retailers under the carbon tax policy, and the high-carbon-emission retailers under combined quotas and tax policy will understate their carbon emissions to increase profits.

Furthermore, this paper uses the revenue sharing contract to coordinate the supply chain under asymmetric carbon information based on different low-carbon policies and gives the value interval of revenue sharing coefficient which could maximize supply chain profits and the optimal revenue sharing fraction which could induce retailer to show his true carbon information under asymmetric carbon information. The numerical analysis shows that the designed contract can induce the retailer with information priority to show his true carbon information and can ensure the cooperative relationship.
This research can be extended in several directions in future work. First, in this work, we consider a two-echelon supply chain. In practice, the supply chain structure is more complicated. This leads to a potential research opportunity to consider the multiechelon or multichannel supply chain under asymmetric carbon information. Second, our research addresses the impact of low-carbon policies on the operational decisions. With the improving environmental awareness, consumers pay more and more attention to lowcarbon products. Therefore, an interesting extension is to examine how supply chain members make decisions when considering consumers' low-carbon preference. Third, our model focuses on the pricing and order quantity decisions. The emission reduction decisions under asymmetric carbon information can be considered in the future.

\section{Appendices}

\section{A. Proof of Lemma 1}

In order to obtain the Stackelberg equilibrium, the best response of the follower should be determined at first. The leader's decision problem is solved based on the follower's response. The retailer's response is as follows: $\partial^{2} f_{A r}^{a} / \partial\left(Q_{A}^{a}\right)^{2}=$ $-\left((2 k-1) / 4 k^{2} Q_{A}^{a}\right)\left(D / Q_{A}^{a}\right)^{1 / 2 k}<0$. Let $\partial f_{A r}^{a} / \partial Q_{A}^{a}=0$; then, the best response of retailer to a wholesale price is given by

$$
Q_{A}^{a^{*}}=\frac{\left[D(2 k-1)^{2 k}\right]}{\left[(2 k)^{2 k}\left(w_{A}^{a}+c_{r}+a_{M r} e_{r}^{a}-a_{\alpha r} e_{r}^{a}\right)^{2 k}\right]} .
$$

When the manufacturer adopts misreporting strategy, the carbon information reflected in the wholesale price should keep consistent with that in his public profit.

In order to convince the retailer to believe the announced carbon information, the manufacturer should decide the wholesale price according to (1). With $\partial^{2} f_{A m h}^{a} / \partial\left(w_{A}^{a}\right)^{2}<0$, we let $\partial f_{A m h}^{a} / \partial w_{A}^{a}=0$; then, we can get, when $F_{1}>0$,

$$
=\frac{w_{A}^{a^{*}}}{=\frac{\left[c_{r}+a_{M r} e_{r}^{a}-a_{\alpha r} e_{r}^{a}+2 k\left(c_{m}+\gamma_{m}^{a} \eta_{m}^{a} a_{M m} e_{m}^{a}-\eta_{m}^{a} a_{\alpha m} e_{m}\right)\right]}{(2 k-1)} .}
$$

Thus, we can get $Q_{A}^{a^{*}}, f_{A m}^{a^{*}}$, and $f_{A r}^{a^{*}}$.

\section{B. Proof of Theorem 2}

When the manufacturer chooses to adopt double factors misreporting strategy, then $f_{A m}^{a^{*}}=f_{A m}^{a 1^{*}}$. When $F_{1}>0$, we can get

$$
\begin{aligned}
\frac{\partial f_{A m}^{a 1^{*}}}{\partial \gamma_{m}^{a 1}} & =\frac{(1-2 k) \eta_{m}^{a 1} a_{M m} e_{m}^{a}\left(\gamma_{m}^{a 1} \eta_{m}^{a 1} a_{M m} e_{m}^{a}-a_{\alpha m} e_{m}^{a} \eta_{m}^{a 1}-a_{M m} e_{m}^{a}+a_{\alpha m} e_{m}^{a}\right)}{D^{-1}(2 k-1)^{1-4 k}(2 k)^{4 k-1}\left(c_{\mathrm{sc}}+\gamma_{m}^{a} \eta_{m}^{a} e_{m}^{a} a_{M m}-\eta_{m}^{a} e_{m}^{a} a_{\alpha m}+e_{r}^{a} a_{M r}-e_{r}^{a} a_{\alpha r}\right)^{2 k+1}}, \\
\frac{\partial f_{d s s}^{a 1^{*}}}{\partial \eta_{m}^{a 1}} & =\frac{(1-2 k)\left(\gamma_{m}^{a 1} a_{M m} e_{m}^{a}-a_{\alpha m} e_{m}^{a}\right)\left(\gamma_{m}^{a 1} \eta_{m}^{a 1} a_{M m} e_{m}^{a}-a_{\alpha m} e_{m}^{a} \eta_{m}^{a 1}-a_{M m} e_{m}^{a}+a_{\alpha m} e_{m}^{a}\right)}{D^{-1}(2 k-1)^{1-4 k}(2 k)^{4 k-1}\left(c_{\mathrm{sc}}+\gamma_{m}^{a} \eta_{m}^{a} e_{m}^{a} a_{M m}-\eta_{m}^{a} e_{m}^{a} a_{\alpha m}+e_{r}^{a} a_{M r}-e_{r}^{a} a_{\alpha r}\right)^{2 k+1}} .
\end{aligned}
$$


Let $H$ be Hessian of $f_{A m}^{a 1^{*}}$. When the following conditions can be satisfied, $H$ exhibits a maximum value:

$$
\begin{aligned}
\gamma_{m}^{a 1} & >0, \\
\eta_{m}^{a 1} & >0, \\
c_{\mathrm{sc}} & +\gamma_{m}^{a 1} \eta_{m}^{a 1} e_{m}^{a} a_{M m}-\eta_{m}^{a 1} e_{m}^{a} a_{\alpha m}+e_{r}^{a} a_{M r}-e_{r}^{a} a_{\alpha r}>0 \\
c_{\mathrm{sc}} & +\left(a_{M m}-a_{\alpha m}\right) e_{m}^{a}+\left(a_{M r}-a_{\alpha r}\right) e_{r}^{a} \\
& >2 k e_{m}^{a}\left(a_{M m} \gamma_{m}^{a 1} \eta_{m}^{a 1}-a_{\alpha m} \eta_{m}^{a 1}-a_{M m}+a_{\alpha m}\right) \\
\left(\gamma_{m}^{a 1}\right. & \left.a_{M m}-a_{\alpha m}\right)^{2}\left[c_{\mathrm{sc}}+\left(a_{M m}-a_{\alpha m}\right) e_{m}^{a}\right. \\
& +\left(a_{M r}-a_{\alpha r}\right) e_{r}^{a} \\
& \left.-2 k e_{m}^{a}\left(a_{M m} \gamma_{m}^{a 1} \eta_{m}^{a 1}-a_{\alpha m} \eta_{m}^{a 1}-a_{M m}+a_{\alpha m}\right)\right] \\
& >0 .
\end{aligned}
$$

Let $\partial f_{A m}^{a 1^{*}} / \partial \gamma_{m}^{a 1}=0$ and $\partial f_{A m}^{a 1^{*}} / \partial \eta_{m}^{a 1}=0$; then, we can get the optimal misreporting equation:

$$
a_{m s} \gamma_{m}^{a a} \gamma_{c}^{a a}-a_{\alpha s} \gamma_{c}^{a a}-a_{m s}+a_{\alpha s}=0
$$

With (B.2), we can conclude that when $a_{M m} \neq a_{\alpha m}$, the optimal misreporting equation above is tenable.

\section{Proof of Theorem 4}

When the manufacturer chooses the double factors misreporting strategy, the misreporting factors should satisfy the following three conditions:

(a) $H_{1}=0$; (b) $\eta_{m}^{a 1} \in\left[e_{L} / e_{m}, e_{H} / e_{m}\right]$; (c) $\gamma_{m}^{a 1} \in$ $\left[a_{m L} / a_{M m}, a_{m H} / a_{M m}\right]$.

Condition (a) can be rewritten as follows: $\gamma_{m}^{a 1}=\left(a_{M m}-\right.$ $\left.a_{\alpha m}\right) / a_{M m} \eta_{m}^{a 1}+a_{\alpha m} / a_{M m}$. With conditions (a) and (b), we can get

$$
\begin{array}{ll}
\gamma_{m}^{a 1} \in\left[a_{M m}^{-1} F_{4}, a_{M m}^{-1} F_{3}\right] & \text { if } a_{M m}>a_{\alpha m} \\
\gamma_{m}^{a 1} \in\left[a_{M m}^{-1} F_{3}, a_{M m}^{-1} F_{4}\right] & \text { if } a_{M m}<a_{\alpha m} .
\end{array}
$$

With condition (c) and (C.1), we can get the confidence interval for the manufacturer to understate his carbon emissions.

$$
\begin{aligned}
Q^{A^{*}} & =\frac{D(2 k-1)^{2 k}\left(1-\phi^{A}\right)^{2 k}}{(2 k)^{2 k}\left(w^{A}+c_{r}+\gamma_{r}^{A} \eta_{r}^{A} e_{r}^{a} a_{M r}-\eta_{r}^{a} e_{r}^{a} a_{\alpha r}\right)^{2 k}}, \\
w^{A^{*}} & =\frac{\left[2 k\left(1-\phi^{A}\right)\left(c_{m}+e_{m}^{a} a_{M m}-e_{m}^{a} a_{\alpha m}\right)+\left(1-\phi^{A}-2 k \phi^{A}\right)\left(c_{r}+\gamma_{r}^{A} \eta_{r}^{A} e_{r}^{a} a_{M r}-\eta_{r}^{A} e_{r}^{a} a_{\alpha r}\right)\right]}{\left(2 k-1+\phi^{A}\right)} .
\end{aligned}
$$

With (23), we can get the actual profit of the retailer:

$$
\begin{aligned}
f_{r}^{A^{*}}= & \frac{2 k\left(1-\phi^{A}\right)\left(c_{m}+a_{M m} e_{m}^{a}-a_{\alpha m} e_{m}^{a}\right)+\left(4 k^{2}-2 k+1-\phi^{A}\right)\left(c_{r}+\gamma_{r}^{A} \eta_{r}^{A} e_{r}^{a} a_{M r}-\eta_{r}^{A} e_{r}^{a} a_{\alpha r}\right)}{D^{-1}(2 k-1)^{1-2 k}\left(2 k-1+\phi^{A}\right)^{1-2 k}(2 k)^{4 k}\left(c_{\mathrm{sc}}+a_{M m} e_{m}^{a}-a_{\alpha m} e_{m}^{a}+\gamma_{r}^{A} \eta_{r}^{A} a_{m r} e_{r}^{a}-\eta_{r}^{a} a_{\alpha r} e_{r}^{a}\right)^{2 k}} \\
& -\frac{D(2 k-1)^{2 k}\left(2 k-1+\phi^{A}\right)^{2 k}\left(e_{r}^{a} a_{M r}-e_{r}^{a} a_{\alpha r}+c_{r}\right)}{(2 k)^{4 k}\left(c_{\mathrm{sc}}+a_{M m} e_{m}^{a}-a_{\alpha m} e_{m}^{a}+\gamma_{r}^{A} \eta_{r}^{A} a_{M r} e_{r}^{a}-\eta_{r}^{a} a_{\alpha r} e_{r}^{a}\right)^{2 k}}+\left(b_{\alpha r}-b_{M r}\right) e_{r}^{a} .
\end{aligned}
$$


Taking the derivative of $f_{r}^{A^{*}}$ with respect to $\gamma_{r}^{A}$ and $\eta_{r}^{A}$, letting $\partial f_{r}^{A^{*}} / \partial \gamma_{r}^{A}=0$ and $\partial f_{r}^{A^{*}} / \partial \eta_{r}^{A}=0$, we can get

$$
\begin{aligned}
& \left(2 k \phi^{A}-1+\phi^{A}\right)\left(c_{m}+e_{m}^{a} a_{M m}-e_{m}^{a} a_{\alpha m}\right) \\
& -\left(4 k^{2}-2 k+1-\phi^{A}\right)\left(c_{r}+\gamma_{r}^{A} \eta_{r}^{A} e_{r}^{a} a_{M r}-\eta_{r}^{A} e_{r}^{a} a_{\alpha r}\right) \\
& +\left(c_{r}+e_{r}^{a} a_{M r}-e_{r}^{a} a_{\alpha r}\right)\left(4 k^{2}-2 k+2 k \phi^{A}\right)=0 .
\end{aligned}
$$

With $\gamma_{r}^{A}=\eta_{r}^{A}=1$, we can get $\phi^{A^{*}}=1 /(2 k+1)$.

Similarly, we can get $\phi^{B^{*}}=1 /(2 k+1)$ and $\phi^{C^{*}}=1 /(2 k+1)$.

\section{G. Threshold Values}

Threshold values are as follows:

$$
\begin{aligned}
& F_{1}=c_{\mathrm{sc}}+\gamma_{m}^{a} \eta_{m}^{a} e_{m}^{a} a_{M m}-\eta_{m}^{a} e_{m}^{a} a_{\alpha m}+e_{r}^{a} a_{M r}-e_{r}^{a} a_{\alpha r}, \\
& F_{2}=c_{\mathrm{sc}}+e_{m}^{a} a_{M s}-e_{m}^{a} a_{\alpha s}+e_{r}^{a} a_{M r}-e_{r}^{a} a_{\alpha r}, \\
& F_{3}=\frac{\left(a_{M m}-a_{\alpha m}\right) e_{m}}{e_{L}}+a_{\alpha m}, \\
& F_{4}=\frac{\left(a_{M m}-a_{\alpha m}\right) e_{m}}{e_{H}}+a_{\alpha m}, \\
& F_{5}=c_{\mathrm{sc}}+a_{M m} e_{m}^{a}-a_{\alpha m} e_{m}^{a}+\gamma_{r}^{a} \eta_{r}^{a} a_{M r} e_{r}^{a}-\eta_{r}^{a} a_{\alpha r} e_{r}^{a}, \\
& F_{6}=\frac{L e_{r}}{c_{L}}+a_{\alpha r}, \\
& F_{7}=\frac{L e_{r}}{c_{H}}+a_{\alpha r}, \\
& F_{8}=\frac{\left(4 k^{2}-2 k\right)}{\left(4 k^{2}-2 k+1\right)}-\frac{\left(c_{\mathrm{sc}}+a_{M m} e_{m}^{b}\right)}{\left(4 k^{2}-2 k+1\right) a_{M r} e_{r}^{b}}, \\
& L \\
& I_{1}=4 k^{2}-2 k+1, \\
& I_{2}=c_{\mathrm{sc}}+\left(a_{M m}-a_{\alpha m}\right)^{+} e_{m}^{c}-a_{\alpha r} e_{r}^{c} . \\
& =\frac{\left[2 k(2 k-1)\left(a_{M r}-a_{\alpha r}\right) e_{r}^{a}-c_{\mathrm{sc}}-a_{M m} e_{m}^{a}+a_{\alpha m} e_{m}^{a}\right]}{e_{r}^{a}\left(4 k^{2}-2 k+1\right)} \\
& H_{1}=a_{M m} \gamma_{m}^{a 1} \eta_{m}^{a 1}-a_{\alpha m} \eta_{m}^{a 1}-a_{M m}+a_{\alpha m}, \\
& H_{2} \\
& =\eta_{r}^{a 1} e_{r}^{a}\left(\gamma_{r}^{a 1} a_{M r}-a_{\alpha r}\right)\left(4 k^{2}-2 k+1\right) \\
& -2 k(2 k-1)\left(a_{M r}-a_{\alpha r}\right) e_{r}^{a}+c_{\mathrm{sc}}+\left(a_{M m}-a_{\alpha m}\right) e_{m}^{a},
\end{aligned}
$$

\section{Conflict of Interests}

The authors declare that there is no conflict of interests regarding the publication of this paper.

\section{Acknowledgments}

This research is partially supported by the National Natural Science Foundation of China (71572058), Soft Science Program of Guangdong Province (2014A070703007,
2015A070704008), and the Fundamental Research Funds for the Central Universities, SCUT (2015ZZ057).

\section{References}

[1] S. F. Du, L. Hu, and M. Song, "Production optimization considering environmental performance and preference in the cap-and-trade system," Journal of Cleaner Production, vol. 112, no. 20, pp. 1600-1607, 2016.

[2] Z. J. Jiang and S. A. Shao, "Distributional effects of a carbon tax on Chinese households: a case of Shanghai," Energy Policy, vol. 73, pp. 269-277, 2014.

[3] C. Y. Lu, Q. Tong, and X. M. Liu, "The impacts of carbon tax and complementary policies on Chinese economy," Energy Policy, vol. 38, no. 11, pp. 7278-7285, 2010.

[4] Z. Wang and C. Wang, "How carbon offsetting scheme impacts the duopoly output in production and abatement: analysis in the context of carbon cap-and-trade," Journal of Cleaner Production, vol. 103, pp. 715-723, 2015.

[5] Y. Su, H. Guo, and X. Wang, "Incentive contract in supply chain with asymmetric information," Discrete Dynamics in Nature and Society, vol. 2014, Article ID 380142, 6 pages, 2014.

[6] F. Adaman, N. Karalidotless, G. Kumbaroĝlu, İ. Or, B. Özkaynak, and Ü. Zenginobuz, "What determines urban households' willingness to pay for $\mathrm{CO}_{2}$ emission reductions in Turkey: a contingent valuation survey," Energy Policy, vol. 39, no. 2, pp. 689-698, 2011.

[7] J. Wei, K. Govindan, Y. Li, and J. Zhao, "Pricing and collecting decisions in a closed-loop supply chain with symmetric and asymmetric information," Computers \& Operations Research, vol. 54, pp. 257-265, 2015.

[8] Q. Lei, J. Chen, X. Wei, and S. Lu, "Supply chain coordination under asymmetric production cost information and inventory inaccuracy," International Journal of Production Economics, vol. 170, pp. 204-218, 2015.

[9] D. Zissis, G. Ioannou, and A. Burnetas, "Supply chain coordination under discrete information asymmetries and quantity discounts," Omega, vol. 53, pp. 21-29, 2015.

[10] L. Yang, C. S. Zheng, and M. H. Xu, "Comparisons of low carbon policies in supply chain coordination," Journal of Systems Science and Systems Engineering, vol. 23, no. 3, pp. 342-361, 2014.

[11] X. Y. Xu, X. P. Xu, and P. He, "Joint production and pricing decisions for multiple products with cap-and-trade and carbon tax regulations," Journal of Cleaner Production, vol. 112, no. 20, pp. 4093-4106, 2016.

[12] B. Li, M. Y. Zhu, Y. S. Jiang, and Z. H. Li, "Pricing policies of a competitive dual-channel green supply chain," Journal of Cleaner Production, vol. 112, no. 20, pp. 2029-2042, 2016.

[13] Y. Liu and Y. Y. Lu, “The economic impact of different carbon tax revenue recycling schemes in China: a model-based scenario analysis," Applied Energy, vol. 141, pp. 96-105, 2015.

[14] G. Allan, P. Lecca, P. McGregor, and K. Swales, "The economic and environmental impact of a carbon tax for Scotland: a computable general equilibrium analysis," Ecological Economics, vol. 100, pp. 40-50, 2014.

[15] P. He, W. Zhang, X. Xu, and Y. Bian, "Production lot-sizing and carbon emissions under cap-and-trade and carbon tax regulations," Journal of Cleaner Production, vol. 103, no. 15, pp. 241-248, 2015.

[16] R. Hammami, I. Nouira, and Y. Frein, "Carbon emissions in a multi-echelon production-inventory model with lead time 
constraints," International Journal of Production Economics, vol. 164, pp. 292-307, 2015.

[17] R. A. Sedjo and G. Marland, "Inter-trading permanent emissions credits and rented temporary carbon emissions offsets: some issues and alternatives," Climate Policy, vol. 3, no. 4, pp. 435-444, 2003.

[18] S. Benjaafar, Y. Li, and M. Daskin, "Carbon footprint and the management of supply chains: insights from simple models," IEEE Transactions on Automation Science and Engineering, vol. 10, no. 1, pp. 99-116, 2013.

[19] F. P. Chiu, H. I. Kuo, C. C. Chen, and C. S. Hsu, "The energy price equivalence of carbon taxes and emissions trading-theory and evidence," Applied Energy, vol. 160, pp. 164-171, 2015.

[20] E. Stanny, "Voluntary disclosures of emissions by US firms," Business Strategy and the Environment, vol. 22, no. 3, pp. 145158, 2013.

[21] Z. Huang, "A study on the supervision system with voluntary information disclosure in Chinese listed companies," International Journal of Business and Management, vol. 3, no. 6, pp. 114117, 2008.

[22] J. Peng, J. Sun, and R. Luo, "Corporate voluntary carbon information disclosure: evidence from China's listed companies," The World Economy, vol. 38, no. 1, pp. 91-109, 2015.

[23] X. Chen, X. Wang, and H. K. Chan, "Channel coordination through subsidy contract design in the mobile phone industry," International Journal of Production Economics, vol. 171, pp. 97104, 2016.

[24] S. Panda, N. M. Modak, M. Basu, and S. K. Goyal, "Channel coordination and profit distribution in a social responsible three-layer supply chain," International Journal of Production Economics, vol. 168, pp. 224-233, 2015.

[25] X. Xu, X. Cheng, and Y. Sun, "Coordination contracts for outsourcing supply chain with financial constraint," International Journal of Production Economics, vol. 162, pp. 134-142, 2015.

[26] J. H. Mortimer, "The effects of revenue-sharing contracts on welfare in vertically-separated markets: evidence from the video rental industry," Harvard Institute Research Working Paper no. 1964, 2002, http://papers.ssrn.com/sol3/papers.cfm? abstract_id=336244.

[27] J. H. Mortimer, "Vertical contracts in the video rental industry," The Review of Economic Studies, vol. 75, no. 1, pp. 165-199, 2008.

[28] G. P. Cachon and M. A. Lariviere, "Supply chain coordination with revenue-sharing contracts: strengths and limitations," Management Science, vol. 51, no. 1, pp. 30-44, 2005.

[29] Z. Qin, "Towards integration: a revenue-sharing contract in a supply chain," IMA Journal of Management Mathematics, vol. 19, no. 1, pp. 3-15, 2008.

[30] H. Krishnan and R. A. Winter, "On the role of revenue-sharing contracts in supply chains," Operations Research Letters, vol. 39, no. 1, pp. 28-31, 2011.

[31] G. Kong, S. Rajagopalan, and H. Zhang, "Revenue sharing and information leakage in a supply chain," Management Science, vol. 59, no. 3, pp. 556-572, 2013.

[32] Z. K. Weng, "Channel coordination and quantity discounts," Management Science, vol. 41, no. 9, pp. 1509-1522, 1995.

[33] M. H. Xu, X. Qi, G. Yu, H. Zhang, and C. Gao, “The demand disruption management problem for a supply chain system with nonlinear demand functions," Journal of Systems Science and Systems Engineering, vol. 12, no. 1, pp. 82-97, 2003.

[34] D. Drake, P. R. Kleindorfer, and L. N. van Wassenhove, "Technology choice and capacity portfolios under emissions regulation," Working Paper, Harvard Business School, 2014, http://papers.ssrn.com/sol3/papers.cfm?abstract_id=1702186.

[35] G. Hua, T. C. E. Cheng, and S. Wang, "Managing carbon footprints in inventory management," International Journal of Production Economics, vol. 132, no. 2, pp. 178-185, 2011.

[36] A. Sadegheih, "Optimal design methodologies under the carbon emission trading program using MIP, GA, SA, and TS," Renewable and Sustainable Energy Reviews, vol. 15, no. 1, pp. 504-513, 2011.

[37] S. F. Du, L. L. Zhu, L. Liang, and F. Ma, "Emission-dependent supply chain and environment-policy-making in the 'cap-andtrade’ system," Energy Policy, vol. 57, pp. 61-67, 2013.

[38] W. A. Pizer, "Combining price and quantity controls to mitigate global climate change," Journal of Public Economics, vol. 85, no. 3, pp. 409-434, 2002. 


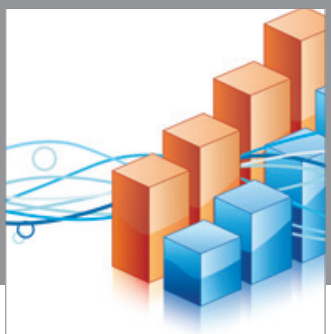

Advances in

Operations Research

vatem alat4

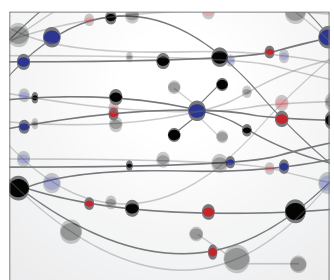

\section{The Scientific} World Journal
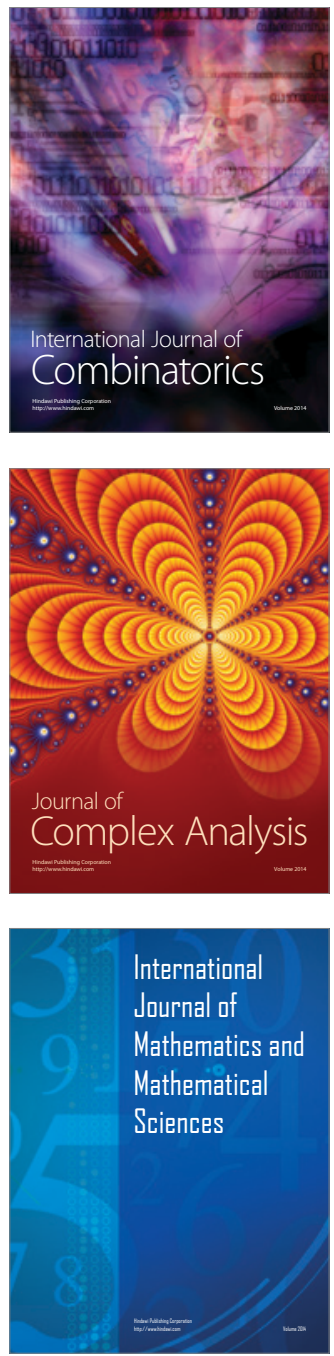
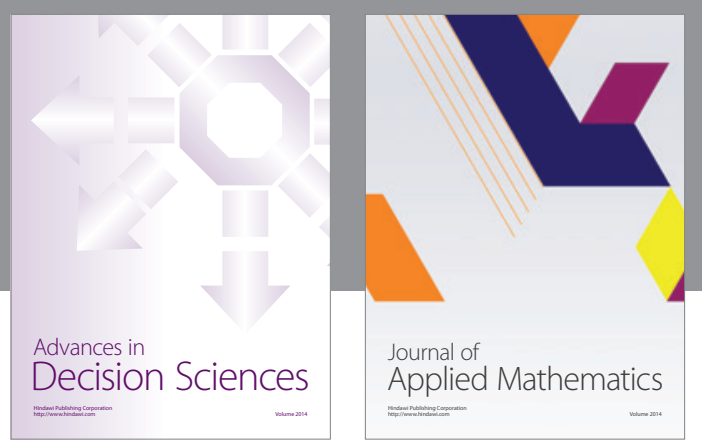

Algebra

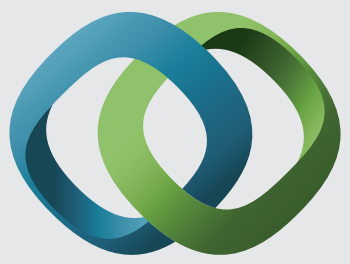

\section{Hindawi}

Submit your manuscripts at

http://www.hindawi.com
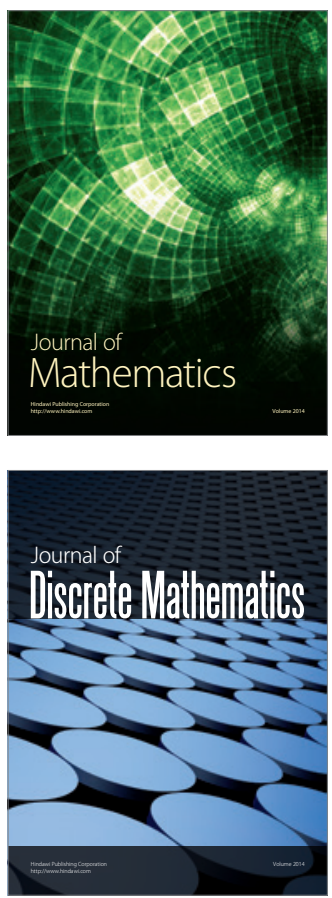

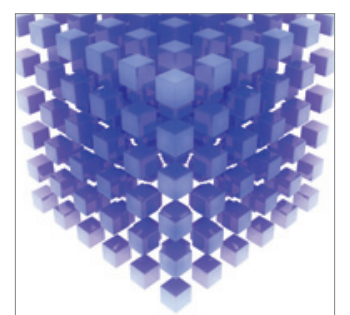

Mathematical Problems in Engineering
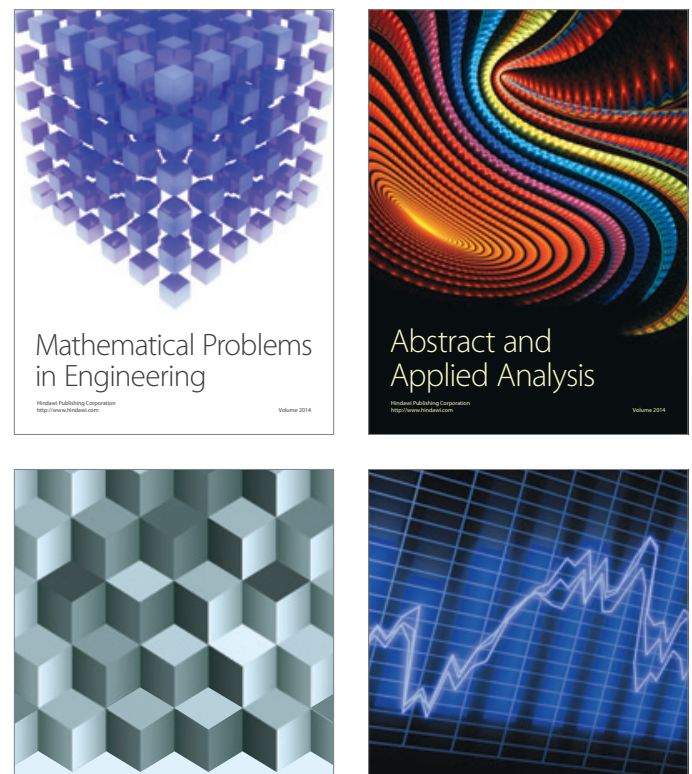

Journal of

Function Spaces

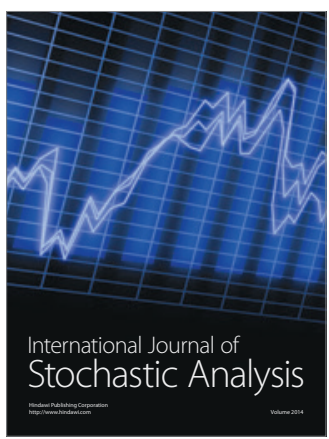

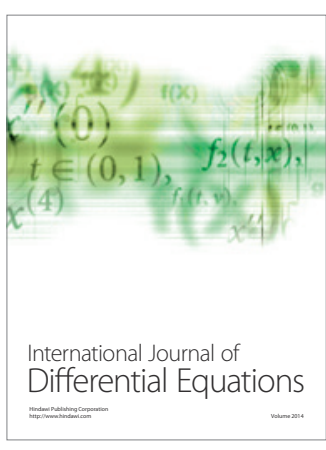
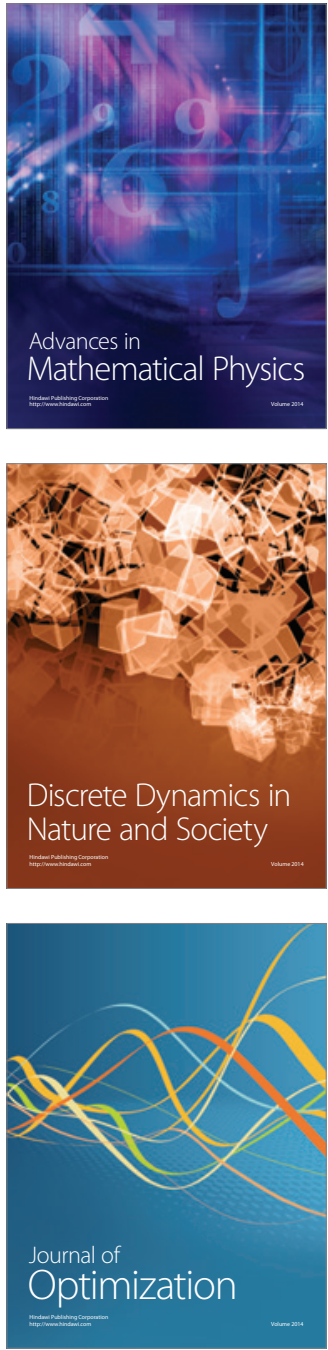